University of San Diego

Digital USD

Spring 5-23-2020

\title{
Using Short Message Services (SMS) to Reduce No-Show Rates an Evidence-Based Practice Project
}

Matthew Rocklage

University of San Diego, mrocklage@sandiego.edu

Follow this and additional works at: https://digital.sandiego.edu/dnp

Part of the Nursing Commons, and the Other Psychology Commons

\section{Digital USD Citation}

Rocklage, Matthew, "Using Short Message Services (SMS) to Reduce No-Show Rates an Evidence-Based Practice Project" (2020). Doctor of Nursing Practice Final Manuscripts. 134.

https://digital.sandiego.edu/dnp/134

This Doctor of Nursing Practice Final Manuscript is brought to you for free and open access by the Theses and Dissertations at Digital USD. It has been accepted for inclusion in Doctor of Nursing Practice Final Manuscripts by an authorized administrator of Digital USD. For more information, please contact digital@sandiego.edu. 


\author{
UNIVERSITY OF SAN DIEGO \\ Hahn School of Nursing and Health Science \\ DOCTOR OF NURSING PRACTICE
}

USING SHORT MESSAGE SERVICES (SMS) TO REDUCE NO-SHOW RATES: AN

EVIDENCE-BASESD PRACTICE PROJECT

by

Matthew Wesley Rocklage

A Doctor of Nursing Practice Portfolio presented to the

FACULTY OF THE HAHN SCHOOL OF NURSING AND HEALTH SCIENCE

UNIVERSITY OF SAN DIEGO

In partial fulfillment of the

requirements for the degree

DOCTOR OF NURSING PRACTICE

May / 2020

Dr. Michael Terry, Faculty Advisor

Alexandra Sietsma DNP, Clinical Mentor 


\section{Table of Contents}

Acknowledgments $\quad$ iv

Opening Statement Purpose in Pursuing the DNP 1

Documentation of Mastery of DNP Program Outcomes 2

Final Manuscript 3

$\begin{array}{ll}\text { Abstract } & 4\end{array}$

$\begin{array}{ll}\text { Description } & 7\end{array}$

$\begin{array}{ll}\text { Evolution } & 10\end{array}$

$\begin{array}{ll}\text { Process Description } & 11\end{array}$

$\begin{array}{ll}\text { Impact } & 12\end{array}$

$\begin{array}{ll}\text { Moving Forward } & 13\end{array}$

$\begin{array}{ll}\text { References } & 15\end{array}$

Concluding Essay: Reflections on Growth in Advanced Practice Nursing Role 19

$\begin{array}{ll}\text { Appendix A IRB Approval } & 20\end{array}$

Appendix B Letter of Support from Clinical Site 22

Appendix C Poster Abstract with Letter of Acceptance to Conference 23

Appendix D Poster Presentation 25

Appendix E PowerPoint Stakeholder Presentation 26 
Appendix F DNP Program Outcomes Exemplars

Appendix G [Other Supporting Documents] 


\section{Acknowledgments}

I thank my father, for whom without his hard work and dedication in life, I would have not been afforded this opportunity to better myself and pursue this level of achievement. Your work ethic, your dedication, and your generosity have inspired me to seek a great level of achievement in life, I love you incredibly, thank you for being my father. To my loving wife, for supporting an older student eager to better himself and strive for what's best for our family, and for whispering words of encouragement and love, thank you I love you.

I thank my faculty advisor, Dr. Michael Terry, for showing me the way, and keeping my head above water during this journey. I thank my clinical preceptor, the incredibly busy and talented Alexandra Sietsma, for her help and support with the continuation of this project. I thank Janelle Kistler for all her help with my staff integrations and data collection, especially amongst her already busy schedule, she was incredibly helpful and always wore a smile. I thank Dr. Steve Koh, for championing this projects continuation to his residents, and the therapist at the clinic, furthering its reach and positive impact at the clinic. I thank all the staff and students at the University of San Diego who have helped and guided me along the way. I thank Kate Todaro for helping me stay the course and meet all the requisite deadlines. 


\section{Opening Statement}

\section{Purpose in Pursuing the DNP}

My motivation in pursuing the doctoral degree is motivated both internally and externally, and this drive is a fire that needs to be continuously nurtured and fed. I find the journey to wisdom is not one with a destination, it is continuous and ongoing. I have always adored and reveled in living in a grey area formed of untethered design, where concepts and understanding are ever evolving. I am drawn by a powerful and unyielding force towards understanding the human mind. As a nurse compassion and caring are requisite and part of a fundamental foundation to who I am, and due to the ever persistent stigma around mental health, change will not be made by throwing electronic twitter responses or out-of-proportion news stories. Change will come from my compassion to help. In order for me to bear the weight, break the stigma, help those who are shunned, and bring awareness, I must first prepare myself. Hence this pursuit of the doctoral degree as a psychiatric nurse practitioner. During this pursuit for knowledge I have been eager to feed my thirst, to expand my toolbox to help as many patients as I can, and most importantly of all, understand that when my journey at the University of San Diego concludes, my education does not. The doctoral degree as a psychiatric nurse practitioner, while a profound achievement, does not mean I am done. For myself and for the betterment of all mental health patients, I will continue to pursue knowledge, advocate for policy change and champion my patients care. 
Documentation of Mastery of DNP Program Outcomes 
SMS to Reduce No-Show Rates: EBP Project

\section{Final Manuscript}

Using Short Message Services (SMS) to Reduce No-Show Rates: An Evidence-Based Project.

Matthew Wesley Rocklage 


\begin{abstract}
Background: No-shows (NS) are correlated with reduced treatment efficacy, increased financial burden on medical institutions, and early treatment termination for therapy. NS occur for a variety of reasons and appointment compliance within outpatient mental health clinics has a wide variance with clinics reporting no-shows ranging from $15 \%$ to $50 \%$. This section of the project is a continuation started by an earlier USD DNP student Fernando Serrano, in which the projects aims were expanded beyond the participation of nurse practitioners only to now include marriage family therapists (MFT), psychologists and medical residents, and to address the NS rates clinic-wide. One year after the initial project was implemented, the year-to-date no-show rates for the entire clinic was $11.40 \%$. For residents it was $12.58 \%$, for nurse practitioners (NP) it was $5.71 \%$, and for MFTs and psychologists it was $12.82 \%$.

Purpose of the Project: Providers and staff will offer patients the ability to sign up for Short Message Services (SMS) appointment reminders. Patients who agree to SMS will receive text messages to their phone with an appointment reminder on the day prior. The goal is to increase SMS use with patients and reduce missed appointments (MA) by 20\% clinic-wide and within each group of clinicians.
\end{abstract}

Framework/EBP Model: The IOWA model was used for this project.

Evidence-Based Intervention: With continual reduced cost and substantial increase in mobile phone technology usage by the general population, SMS has become a new mainstay for direct communication. SMS appointment reminders have been successfully implemented in mental health, radiology, physical therapy, and dentistry with each setting experiencing a significant decrease in no-show rates. 
Implementation: After clinic and university IRB approval, SMS teaching material, printouts and reminder notes for providers were prepared. Qualitative statements from the three disciplines about attitude and barriers regarding SMS collected before, during and after the project's implementation. Pre-data collection included surveying MA rates among all clinic patients for the previous 8 weeks.

15-30-minute teaching sessions took place with psychiatric mental health nurse practitioners (PMHNP), PMHNP students, MFT's, psychologists, residents, and administration staff. SMS "How to" flyers posted in provider communal areas and in each provider room to instruct and remind providers and staff to offer SMS reminders to patients. Data was collected weekly for 8 weeks examining MAs and provider/staff SMS compliance with offering SMS to patients. Data was continually collected on secured hard drives on excel spreadsheets. Data was generated from reports without any patient identification information.

Evaluation Results: We expected at least $50 \%$ of the providers/students/staff would report they are offering SMS to patients at the end of the first 4 week and at least $75 \%$ by the end of 8 weeks. We predicted at least $70 \%$ SMS signup with patients and a reduction in no-show rates by $20 \%$ upon project completion.

Implications for Clinical Practice: We anticipated all providers and staff at the clinic would offer SMS sign up as a part of standard policy and procedure. As SMS sign ups grows, NS will decrease. With a further decrease in clinic wide no-show rates, this program could possibly be rolled out to other UCSD clinic sites.

Conclusions: The brevity, efficiency and cost-effectiveness of SMS allows patients to quickly be reminded of upcoming appointments with the choice to confirm or reschedule 
SMS to Reduce No-Show Rates: EBP Project

as needed. SMS helps increase appointment attendance while reducing provider nonproductive hours from no-shows. 
Using Short Message Services (SMS) to Reduce No-Show Rates: An Evidence-Based Project.

\section{Description}

No-shows (NS) or Missed Appointments (MAs) within the healthcare environment have ever increasing effects on patient care beyond monetary loss (Filippidou, Lingwood, \& Mirza, 2014). No-shows in mental health care, are highly correlated with reduced treatment efficacy, delayed care, negative health outcomes and early termination of treatment (DeFife JA, Conklin CZ, Smith JM, \& Poole J, 2010). Scheduled appointment compliance rates within various outpatient settings has have a wide variance with clinics reporting no-show rates as low as $15 \%$ to as high as $50 \%$ (Car J, Gurol-Urganci I, de Jongh T, Vodopivec-Jamsek V, \& Atun R. 2013). No-shows occur for a variety of reasons including, but not limited to severity of illness, financial/geographical constraints, transportation issues (Filippidou, Lingwood, \& Mirza, 2014). The most common reason given for nonattendance was failure to remember the scheduled appointment entirely (Andel, E., Been, S. K., Rokx, C., \& van der Ende, M. E., 2016).

Fortunately, today's electronic health records (EHR), have built in technology that can aid patients in remembering their appointments. Technology today has afforded human civilization a more rapid and effective way to communicate (Klasnja P, Pratt W, Klasnja, P., \& Pratt, W. 2012). With the proliferation of smart phones on the market and their ease of use, Short Message Services (SMS) access has allowed a new way for patients and providers to communicate (Ronen, K, et al. 2018). A meta-analysis of studies between 2005 and 2015 that investigated the effect of utilizing SMS reminders to reduce no-show rates, concluded that SMS appointment reminders are an effective 
method in improving appointment attendance ( Boksmati, N., Butler-Henderson, K., Anderson, K., \& Sahama, T., 2016). It is also important to note, that while socioeconomic factors may play a role in the owning of a smart phone, even populations such as the homeless are afforded access to these smart phone devices capable of SMS services through outreach programs in their local community (Moczygemba, L. R, et al. 2017). In fact, mobile SMS are well received in the homeless population and are preferred way to communicate in this mobile population (Asgary, R., et al., 2015).

Today SMS contact and services are utilized to help patients with a variety of issues from medication adherence, refill reminders and appointment reminders (Car J, Gurol-Urganci I, de Jongh T, Vodopivec-Jamsek V, \& Atun R., 2013). SMS appointment reminders are being used to remarkable success in countries around the world. In England the major source of missed appointments appears to be insufficient communication and SMS reminders are viewed as providing an instant and asynchronous means of communication that protects patient privacy (Car J, Ng C, Atun R, \& Card A., 2008). In Saudi Arabia after a randomized control trial showed significant improvement with SMS reminders, patients who took part in the trial preferred to continue to receiving SMS reminders in the future (Youssef, A., 2014). In Nigeria they applied SMS reminders to mental health to address patient attendance with first-episode psychosis who were seeking treatment and saw results that reduced the missed appointment rate by half (Thomas, I. F., Lawani, A. O., \& James, B. O., 2017). Even in different disciples such as Dentistry in Scotland, when trialing SMS appointment reminders the number of no-shows reduced significantly (Perry JG., 2011). 
In the modern world today's patients highly prefer SMS appointment reminders over automated and live voices calls, this holds especially paramount for the younger generation and technologically proficient groups (Narring, F., et al. 2013). With the mobile phone penetration rising every year, the utilization of SMS reminders with its cheaper cost and lower use of resources only increase value as a tool to reduce missed appointments (Junod Perron, N, 2013).

This is the second version of this project, originally rolled out and implemented in the spring of 2019 by Fernando Serrano, DNP at Outpatient Psychiatric Services Hillcrest (OSPH) run by the University of California San Diego (UCSD). OPSH serves the community as an outpatient mental health clinic servicing private and publicly insured patients who suffer from a variety of mental health disorders. At OPSH before initial rollout of this project in spring of 2019, the average no-show rate for patients seeing Psychiatric Mental Health Nurse Practitioners (PMHNPs) averaged 18\%. At the end of 2019 , that rate dropped to $5 \%$. The first round of the project was a success. For the second round of the project, the application was expanded to all disciplines within the clinic. At the beginning of 2020, when the second round began, no-show rates for PMHNPs was $13.63 \%$, therapists $12.39 \%$ and medical residents $13.85 \%$.

While the initial project implementation was solely focused on the PMHNPs, the standard of practice used by OPSH to remind patients of their scheduled appointments remained as TeleVox, an automatic phone call service for other service providers such as therapists and medical residents. TeleVox is an automated program which calls patients on the day before their appointment and leaves a voice message about the date, and time of their appointment. Patients are not automatically signed up for SMS due to 
vulnerabilities associated with smart phone devices, and security concerns such as messages that may be seen by third parties, stolen/lost devices, or limited connection ability (Ossemane, E. B., Moon, T. D., Were, M. C., \& Heitman, E., 2018). SMS reminders require an active signup process, so expanding of this project's function to include all disciplines in the clinic required educating these additional clinicians on how to sign up a patient for SMS reminders. The began the focus for round 2 of this project.

Unfortunately, as with the first project run, the data collection period was affected; this time due to a delayed start date and the onset of the COVD19 pandemic. The circumstances affected the project by shortening the data collection window and then creating data outliers during the transition stage from inpatient visits to video visits, in accordance to the stay-at-home orders put in place here in the state of California.

\section{Evolution}

The goal of this second round iteration of the project was to expand the success of the first to the all providers in the clinic and to reduce the no-show rates for the OPSH clinic. The mental health patient population has difficulties with patient compliance with appointment attendance, which leads to improper assessment and a deterioration of essential foundational care (Youssef, A. (2014). The population serviced by the other disciplines at OPSH, the therapists and medical residents, are diverse demographically and culturally distinct, although most to all these patients have access to a smart phone. Fortunately OPSH continues to utilize the EHR known as EPIC, which is essential to the continuation of this project as it has built-in automated SMS reminder settings, which are verbally elected by the patient to be utilized and easily activated. When the patient consents to SMS reminders, the patient receives a SMS reminder the day before their 
appointment, which identifies the receiver by name and reminds them of their appointment day, time, and place. Additionally, the patient is given the choice to confirm or cancel, which if there is a cancellation allows dynamic changes in the days schedule or room for unplanned emergent situations.

The second round of the project trained staff how to offer patients the choice to change their appointment reminders from TeleVox to SMS. This was achieved through two ten-minute in-service sessions which were performed at monthly staff meetings when attendance was high for PHMNPs, PMHNP students, administrative staff, therapists, and medical residents. SMS in-services consisted of two major components; a visual guide with step-by-step instructions on how to perform SMS signups once verbal consent was given, and laminated popup desk reminders for visual cues for providers to remember to ask their patients about SMS signup. In regards to the implementation cost of this project, it was incredibly low, EPIC EHR already had SMS services built in, and paper materials for visual guides and pop up reminders inexpensive, and can be utilized or reproduced for a third round of this project or its expansion to other sites.

\section{Process Description}

Round two of this project continued to be conducted solely at OPSH and utilize the IOWA model as a guide to its formulation and continuation. OPSH is a publicly funded and UCSD operated clinic in the downtown San Diego area, the data evaluation period lasted for 2 months, February 2020 to April 2020, with baseline data collected in January 2020. Data collection was monthly from February 2020 to April 2020, which examined the no-show rates based on provider discipline; PHMNPs, therapists and medical residents. Informally surveys conducted with all participating staff to assess 
compliance with offering SMS to patients and any barriers that arose. During this project, data was retrieved via built in report generators from the EHR software which did not attach any patient identifiers or personal information and were limited to percentage values based on attendance in the date range requested.

\section{Impact}

The second round of this project, in its limited run, again showed success in reducing no-show rates amongst providers at the OPSH clinic. From January 2020 to April 2020, no-show rates for PMHNPs went from $13.67 \%$ to $7.1 \%$, and medical residents went from $13.98 \%$ to $11.30 \%$. However, therapists saw an increase from $12.59 \%$ to $14.44 \%$. Those contributing factors are discussed later. Data from April 2020 onward would be potentially skewed as currently all visits have been converted to video visits only due to the COVID19 pandemic and might function as a positive outlier.

The project continues to remain economically sound as an investment, with a low cost only in paper products, pop up stands, and laminated reminder cards for all providers and staff, a value of $\$ 310$, in comparison to the average no-show cost $\$ 200$. With a minimum of ten less no-shows, the project creates a return on investment of $545 \%$. Important to note, printed materials and education can be reused and reproduced to expand this project to other sites at even lower cost.

\section{Moving forward}

This second round of the project completed its initial purpose; to educate the entire multidisciplinary staff OPSH clinic to sign-up patients for SMS reminders, and to reduce the no-show rates amongst all providers. The project's real value is its impact on 
the clinic with a decrease in lost revenue, increase in provider productivity, and most importantly an increased patient face-to-face time for proper and thorough assessments and possibly increased patient satisfaction.

Contributing factors that may have affected the results can be attributed initially due to the flu season effect on attendance, which was later compounded by the rapidly increasing effects on society of the COVID19 pandemic and its subsequent stay-at-home orders here in the state of California. Both the flu season and COVID19 had its effect on providers as well, adding another element to the data, that can be illustrated in the jump in therapy no-show rates, when the number of available therapist dropped in February due to illness. As video visits became the standard mid to late march, providers where less focused on asking patients about SMS reminders and more focused on performing the video visit efficiently since they not conducted video visits before, and required education on how to do so.

One of the project's first possible improvements was including all multidisciplinary providers on the project, which successfully evolved into this round's main focus. Moving forward, a continuation of this project would include a reeducation about the importance of SMS reminders even during the use of video visits as society adjusts to social distancing during the pandemic. The project will hopefully be continued by oncoming PHMNP students who are part of the OPSH rotation, incorporating improvements mentioned and proposing, through their multi-site rotations, that this project be implemented at other UCSD clinical sites.

In conclusion, in a technology adept society with a high daily smart phone use rate, this project is a valuable part in addressing no-show rates amongst today's patients. 
SMS reminders offer a more convenient and alternative method to patient's appointment reminders over automated voice calls. SMS reminders not only benefit the patient outcome, they can also benefit the clinics, in recovery of revenue and increased provider productivity with more patients attending their scheduled appointments. In the mental health field, attendance to appointments for patient provider interaction and assessment is crucial to the success of the patient and their treatment plan. Something as easy an SMS reminder with a low cost, can have a significant impact. 


\section{References}

1. Andel, E., Been, S. K., Rokx, C., \& van der Ende, M. E. (2016). Risk factors in an HIV-infected population for refraining from specialist care. AIDS Care, 28(10), 1255-1260. https://doi-

org.sandiego.idm.oclc.org/10.1080/09540121.2016.1168914

2. Asgary, R., Sckell, B., Alcabes, A., Naderi, R., Adongo, P., \& Ogedegbe, G. (2015). Perceptions, Attitudes, and Experience Regarding mHealth Among Homeless Persons in New York City Shelters. Journal of Health Communication, 20(12), 1473-1480. https://doiorg.sandiego.idm.oclc.org/10.1080/10810730.2015.1033117

3. Boksmati, N., Butler-Henderson, K., Anderson, K., \& Sahama, T. (2016). The Effectiveness of SMS Reminders on Appointment Attendance: a Meta-Analysis. Journal of Medical Systems, 40(4), 1-10. https://doiorg.sandiego.idm.oclc.org/10.1007/s10916-016-0452-2

4. Brown, W., Giguere, R., Sheinfil, A., Ibitoye, M., Balan, I., Ho, T., Benjamin, Q., Javier, R., Alex, C., Ross, D., Brown, W., 3rd. (2018). Challenges and solutions implementing an SMS text message-based survey CASI and adherence reminders in an international biomedical HIV PrEP study (MTN 017). Journal of Biomedical Informatics, 80, 78-86. https://doiorg.sandiego.idm.oclc.org/10.1016/j.jbi.2018.02.018

5. Car, J., Ng, C., Atun, R., \& Card, A. (2008). SMS text message healthcare appointment reminders in England. Journal of Ambulatory Care Management, 31(3), 216-219. 
https://sandiego.idm.oclc.org/login?url=http://search.ebscohost.com/login.aspx?di rect $=$ true $\& d b=$ rzh \&AN $=105666868 \&$ site $=$ ehost-live

6. Car, J., Gurol-Urganci I, de Jongh, T., Vodopivec-Jamsek, V., \& Atun, R. (2013).

Mobile phone messaging reminders for attendance at healthcare appointments. Cochrane Database of Systematic Reviews, (12), N.PAG.

https://sandiego.idm.oclc.org/login?url=http://search.ebscohost.com/login.aspx?di rect $=$ true $\& \mathrm{db}=\mathrm{rzh} \& \mathrm{AN}=108151807 \&$ site $=$ ehost-live

7. DeFife, J.A., Conklin, C.Z., Smith, J.M., \& Poole, J. (2010). Psychotherapy appointment no-shows: rates and reasons. Psychotherapy, 47(3), 413-417. https://doi-org.sandiego.idm.oclc.org/10.1037/a0021168

8. Filippidou, M., Lingwood S., \& Mirza. I. (2014). Reducing non-attendance rates in a community mental health team. BMJ Open Quality, 3(1) https://doiorg.sandiego.idm.oclc.org/10.1136/bmjquality.u202228.w1114

9. Junod Perron, N., Dao, M. D., Righini, N. C., Humair, J. P., Broers, B., Narring, F., Haller, D. M., \& Gaspoz, J. M. (2013). Text-messaging versus telephone reminders to reduce missed appointments in an academic primary care clinic: a randomized controlled trial. BMC health services research, 13, 125. https://doi.org/10.1186/1472-6963-13-125

10. Klasnja, P., Pratt, W., Klasnja, P., \& Pratt, W. (2012). Healthcare in the pocket: mapping the space of mobile-phone health interventions. Journal of Biomedical Informatics, 45(1), 184-198. https://doiorg.sandiego.idm.oclc.org/10.1016/j.jbi.2011.08.017 
11. Moczygemba, L. R., Cox, L. S., Marks, S. A., Robinson, M. A., Goode, J. R., \& Jafari, N. (2017). Homeless patients' perceptions about using cell phones to manage medications and attend appointments. International Journal of Pharmacy Practice, 25(3), 220-230. https://doiorg.sandiego.idm.oclc.org/10.1111/ijpp.12321

12. Narring, F., Perron, N. J., Dao, M. D., Righini, N. C., Humair, J.-P., Broers, B., ... Haller, D. M. (2013). Text-messaging to reduce missed appointment in a youth clinic: a randomised controlled trial. Journal of Epidemiology \& Community Health, 67(10), 888-891. https://doi-org.sandiego.idm.oclc.org/10.1136/jech$2013-202510$

13. Ossemane, E. B., Moon, T. D., Were, M. C., \& Heitman, E. (2018). Ethical issues in the use of SMS messaging in HIV care and treatment in low- and middle-income countries: case examples from Mozambique. Journal of the American Medical Informatics Association, 25(4), 423-427. https://doiorg.sandiego.idm.oclc.org/10.1093/jamia/ocx123

14. Perry, J.G. (2011). A preliminary investigation into the effect of the use of the short message service (SMS) on patient attendance at an NHS Dental Access Centre in Scotland. Primary Dental Care: Journal of the Faculty of General Dental Practitioners, 18(4), 145-149.

https://sandiego.idm.oclc.org/login?url=http://search.ebscohost.com/login.aspx?di rect $=$ true $\& d b=$ rzh \&AN $=108196205 \&$ site $=$ ehost-live

15. Ronen, K., Unger, J. A., Drake, A. L., Perrier, T., Akinyi, P., Osborn, L., Matemo, Daniel; O’Malley, Gabrielle; Kinuthia, John;John-Stewart, G. (2018). SMS 
SMS to Reduce No-Show Rates: EBP Project

messaging to improve ART adherence: perspectives of pregnant HIV-infected women in Kenya on HIV-related message content. AIDS Care, 30(4), 500-505. https://doi-org.sandiego.idm.oclc.org/10.1080/09540121.2017.1417971

16. Thomas, I. F., Lawani, A. O., \& James, B. O. (2017). Effect of short message service reminders on clinic attendance among outpatients with psychosis at a psychiatric hospital in Nigeria. Psychiatric Services, 68(1), 75-80. https://doiorg.sandiego.idm.oclc.org/10.1176/appi.ps.201500514 15

17. Youssef, A. (2014). Use of short message service reminders to improve attendance at an internal medicine outpatient clinic in Saudi Arabia: a randomized controlled trial. Eastern Mediterranean Health Journal, 20(5), 317-323. https://sandiego.idm.oclc.org/login?url=http://search.ebscohost.com/login.aspx?di rect $=$ true $\& d b=$ rzh \&AN $=103959487 \&$ site $=$ ehost-live 


\section{Concluding Essay:}

\section{Reflections on Growth in Advanced Practice Nursing Role}

From year one to the final moment, it truly has been an incredible journey. Went from starting as a family nurse practitioner to switching to psychiatric mental health nurse practitioner less than a year in. It was the undiscovered frontier of mental health that lured me in. Of course, once I made the switch, I initially panicked as all the previous years of nursing experience did not mean much once I sat down in my first rotation across from a patient! It was that moment that motivated me to be the biggest sponge I could be at my clinical rotations, and to really make conscious connections between my classes and my clinicals. I knew I had to build up a toolbox and I had to do it quick, but for me, nothing solidifies in my mind until I use it, so taking the lessons I learned and seeing them in clinical practice really began building a solid foundation, and my worries lessened for a time. Of course, we all have new and more things to worry about, but I know how to reframe those uncomfortable and unknown experiences and lessons and thus tools as time progressed. Now I find myself, not ready per se nor a complete package of a provider, but more so I know the importance of and continue to seek evidence-based knowledge to better my patient care and increase confidence in myself to be safe, and thorough. It has been an excellent challenging three years, for which I am eternally grateful for all of those who held shape me along the way. 


\section{Appendix A}

\section{IRB Approval}

\section{Date: 4-16-2020}

IRB \#: IRB-2020-35

Title: Using Short Message Services (SMS) to Reduce No-Show Rates: An EBP Project

Creation Date: 10-3-2019

End Date:

Status: Approved

Principal Investigator: Matthew Rocklage

Review Board: USD IRB

Sponsor:

Study History

$\begin{array}{ll}\text { Submission Type Initial } & \text { Review Type Exempt }\end{array} \begin{aligned} & \text { Decision No Human Subjects } \\ & \text { Research }\end{aligned}$

Key Study Contacts

\begin{tabular}{lll}
\hline Member Matthew Rocklage & Role Principal Investigator & $\begin{array}{l}\text { Contact } \\
\text { mrocklage@sandiego.edu }\end{array}$ \\
\hline Member Michael Terry & Role Primary Contact & Contact mjterry@SanDiego.edu \\
\hline
\end{tabular}




\section{UNIVERSITY OF CALIFORNIA, SAN DIEGO HUMAN RESEARCH PROTECTIONS PROGRAM}

Date: $\quad$ December 8,2019

To: Dr. Matthew Rocklage

Re: $\quad$ Project \#191869QI

Using Short Message Services (SMS) to Reduce No-Show Rates

Dear Dr. Rocklage:

Your project has been reviewed by the Director of the UCSD HRPP, IRB Chair, or IRB Chair's designee and is certified as not qualifying as human subjects research according to the Code of Federal Regulations, Title 45, part 46 and UCSD Standard Operating Policies and Procedures; and therefore, does not require $\mathrm{IRB}$ review.

In order for a project to be considered human subjects research, both of the following must be true:

1. The activity is a systematic investigation, including research development, testing and evaluation. A systematic investigation is an activity that attempts to answer a research question or questions that is methodology driven in that it collects data or information in an organized and consistent way, and the data or information is analyzed in some way, be it quantitative or qualitative data and conclusion or conclusions are drawn from the results.

2. The activity is designed to develop or contribute to generalizable knowledge. Generalizable knowledge is defined as an activity that is designed (with intent) to collect information about some individuals to draw general conclusions about other individuals that are predictive of future events and that can be widely applied as expressed in theories, principles, and statements and that enhance scientific or academic understanding.

In order for a project to involve human participants, the following must be true:

1. The investigator will obtain data about living individuals through intervention or interaction with the individual or the information is individually identifiable.

Though certified as not human subjects research, the investigator should ensure that the activities associated with the project are conducted in compliance with applicable UCSD and Rady Children's Hospital - San Diego policies and ethical standards as well as local, state, and federal regulations. 
Appendix B

\title{
Letter of Support from Clinical Site
}

\author{
UCSD Outpatient Psychiatric Services - Hillcrest \\ 140 Arbor Drive \\ San Diego, CA 92103
}

To: Institutional Review Board, University of San Diego

From: Alexandra Sietsma, APRN, PMHNP

Re: Use of Clinical Data

During Fall semester of 2019 and Spring semester of 2020, Mr. Matthew Rocklage did a clinical residency at the UCSD OPSH Clinic as a part of his coursework for the Doctor of Nursing Practice (DNP) Program at the University of San Diego. Mr. Rocklage is now requesting the use of data from this clinical residency for an evidence-based class project.

UCSD Human Research Protections Program (HRPP) has certified this project as a EBP/QA/or QI project and has determined it as not research based. This data does not include PHI or institutional identifiers. I am supportive of Mr. Rocklage using this collected data under the above certification for his class project.

If you have any questions, please do no hesitate to contact me at 619-543-6355 or asietsma@ucsd.edu

Sincerely,

Alexandra Sietsma, APRN, PMHNP-BC

Director, Nurse Practitioner Clinical Training Program

Department of Psychiatry

University of California, San Diego 


\title{
Appendix C
}

\section{Poster Abstract with Letter of Acceptance to Conference}

\author{
Abstract \\ INFORMATION AND TECHNOLOGY \\ Using Short Message Services (SMS) to Reduce No-Show Rates: An EBP Project \\ Matthew Rocklage, BSN, RN \\ DNP/PMHNP Student \\ University of San Diego \\ San Diego, CA
}

Background: No-shows (NS) are correlated with reduced treatment efficacy, increased financial burden on medical institutions, and early treatment termination for therapy. NS occur for a variety of reasons and appointment compliance within outpatient mental health clinics has a wide variance with clinics reporting no-shows ranging from $15 \%$ to $50 \%$. This section of the project is a continuation started by an earlier USD DNP student Fernando Serrano, in which the projects aims will now expand past just nurse practitioners to include marriage family therapist (MFT), psychologist and medical residents, and address the NS rates clinic wide.

At the project clinic, a year after the initial project was implemented the year to date noshow rates for the entire clinic is $11.40 \%$, for Residents it is $12.58 \%$, for Nurse Practitioners (NP) it is 5.71\%, and for MFT's and Psychologist it is $12.82 \%$.

Purpose of the Project: Providers and staff will offer patients the ability to sign up for Short Message Services (SMS) appointment reminders. Patients who agree to SMS will receive text messages to their phone with an appointment reminder on the day prior. The goal is to increase SMS use with patients and reduce MA's by $20 \%$ clinic wide and within each group of NP's, therapist, and residents.

Framework/EBP Model: The IOWA model was used for this project.

Evidence-Based Intervention: With continual reduced cost and substantial increase in mobile phone technology usage by the general population, SMS has become a new mainstay for direct communication. SMS appointment reminders have been successfully implemented in mental health, radiology, physical therapy, and dentistry with each setting experiencing a significant decrease in no-show rates.

Implementation: After clinic IRB approval, SMS teaching material, printouts and reminder notes for providers were prepared. Qualitative statements from the three 
disciplines about attitude and barriers regarding SMS were collected before, during and after the project's implementation. Pre-data collection includes surveying MA's rates and SMS sign up among all clinic patients for the previous 8 weeks.

15-30-minute teaching sessions will take place with psychiatric mental health nurse practitioners (PMHNP), PMHNP students, MFT's, psychologist, residents, and administration staff. SMS "How to" flyers were posted in provider communal areas and in each provider room to instruct and remind providers and staff to offer SMS reminders to patients. Data were collected weekly for 8 weeks examining SMS sign up rates, MAs and provider/staff SMS compliance with offering SMS to patients. Data were continually collected on secured hard drives on excel spreadsheets. Case identifiers were limited to alpha numeric codes with no personal information attached.

Evaluation Results: We expect at least $50 \%$ of the providers/students/staff will report they are offering SMS to patients at the end of the first 4 week and at least $75 \%$ by the end of 8 weeks. We predict at least 70\% SMS sign up with patients and a reduce in noshow rates by $20 \%$ upon project completion.

Implications for Clinical Practice: We anticipate all providers and staff at the clinic will offer SMS sign up as a part of standard policy and procedure. As SMS sign ups grows, NS will decrease. With a further decreased in clinic wide no-show rates, this program could possible be rolled out to other UCSD clinic sites.

Conclusions: Using SMS appointment reminders supplies an additional deterrent for noshows to scheduled appointments. The brevity, efficiency and cost-effectiveness of SMS allows patients to quickly be reminded of upcoming appointments with the choice to confirm or reschedule as needed. SMS helps increase appointment attendance while reducing provider nonproductive hours from no-shows.

\section{Acceptance Letter}

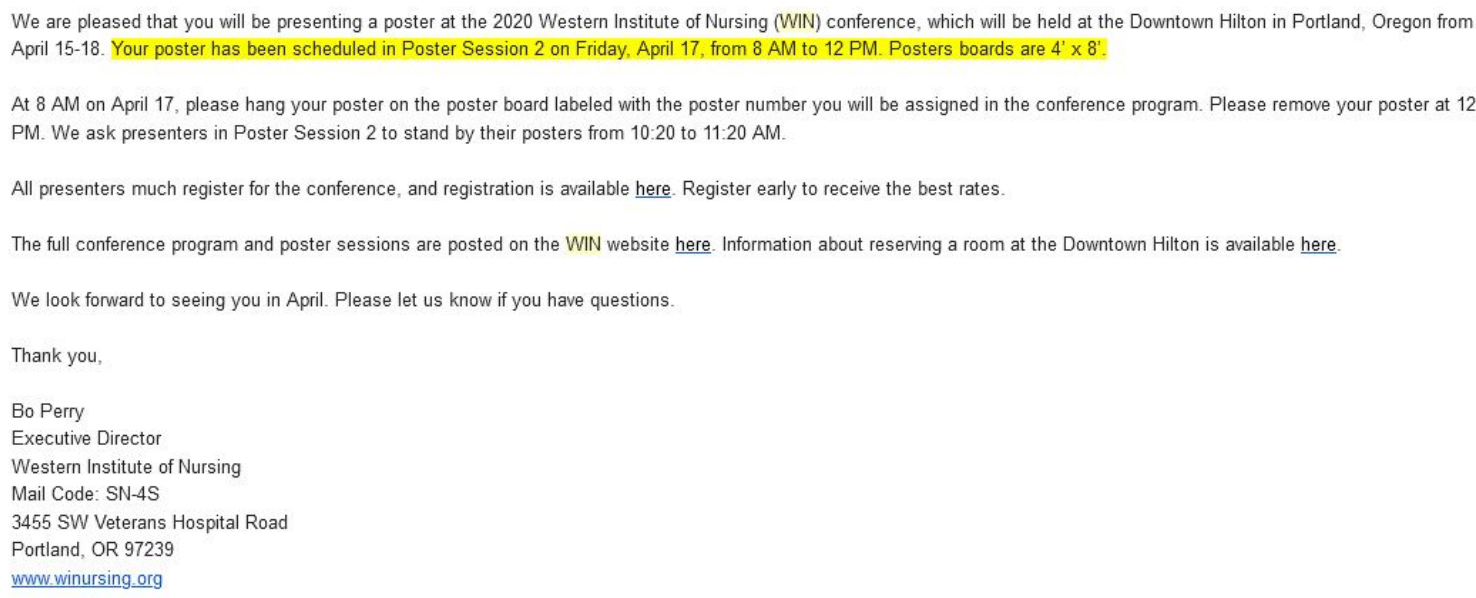




\section{Appendix D}

\section{Poster Presentation}

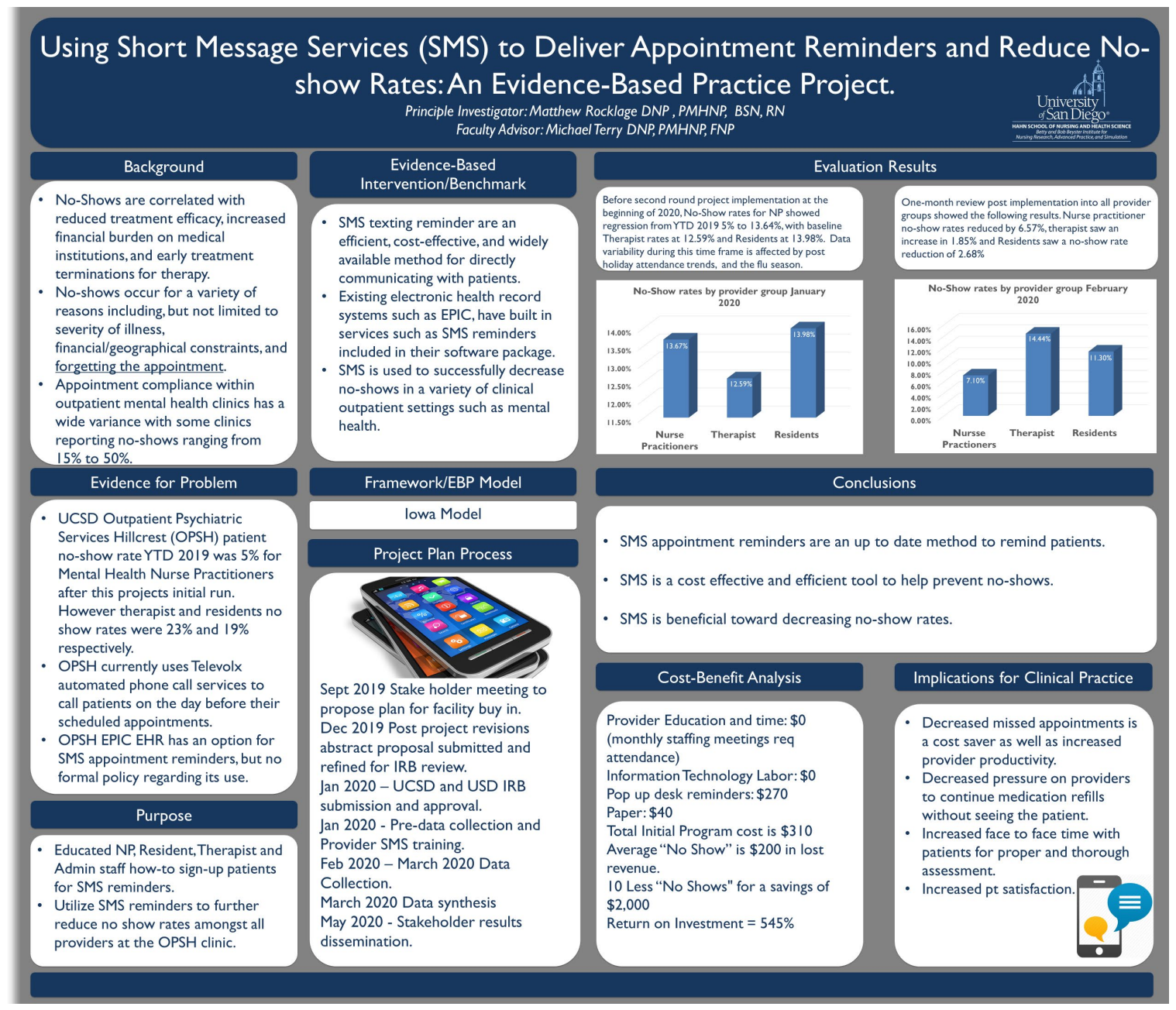




\section{Appendix E}

\section{PowerPoint Stakeholder Presentation}

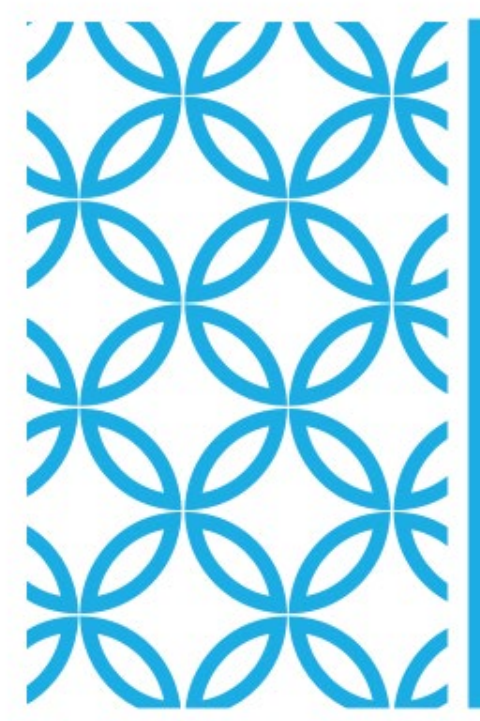

\section{SMS APPOINTMENT REMINDERS}

V2:

Using Short Message Services (SMS) to reduce No Show rates at Hillcrest Outpatient Psychiatric Services (OPS).

The initial run of this project reduced Nurse Practitioner no show rates to 5\% YTD 2019.

\section{WE CONTINUE TO HAVE A PROBLEM WITH NO SHOWS.}

However, therapist and residents no show rates were $23 \%$ and $19 \%$ respectively.

The second run of this project was aimed at address the clinic as a whole and expanding appointment reminders to all disciplines. 


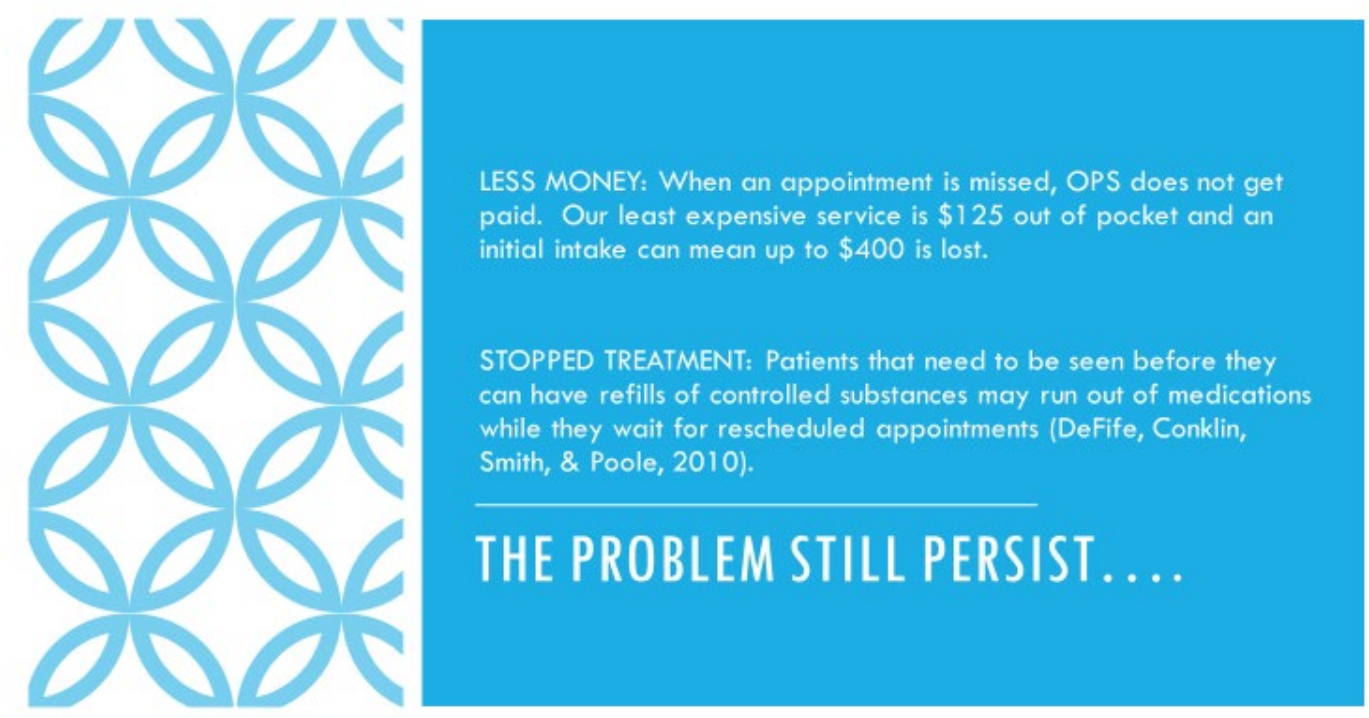

HOW DO WE CURRENTLY REMIND PEOPLE ABOUT THEIR APPOINTMENTS?

First, we schedule an appointment with them and hand an appointment reminder card.

Or they call us to schedule an appointment.

A P P O I N T M E N T
$\sim$ Reminder $\sim$

FOR:

DATE:

$\square$ Mon $\square$ Tue $\square$ Wed $\square$ Thu $\square$ Fri $\square$ Sat $\square$ Sun TIME: a.m. p.m.

On they day before their appointment, TeleVox calls patients up to remind them they have an appointment the next day. 
THIS METHOD IS NOT UP TO DATE WITH TODAYS TECHNOLOGY PREFERENCES.
No shows occur for a variety of reasons including, but not limited to severity of illness, financial/geographic constraints, but forgetting the appointment is the most common reason(Filippidou, Lingwood, \& Mirza,2014).

Patients often report they don't check voicemail immediately on the same day or answer phone numbers not listed under contacts. (Lockhart, Gillespie, \& Grant, 2017).

\section{UTILIZING EXISTING PREFERRED METHODS OF COMMUNICATION: TEXTING}

Texting is the most used app on smartphones, $97 \%$ of Americans using it at least once a day.

Text messages have a $98 \%$ open rate, while email has only a $20 \%$ open rate

On average, Americans exchange twice as many texts as they do calls (Klasnja \& Pratt, 2012).

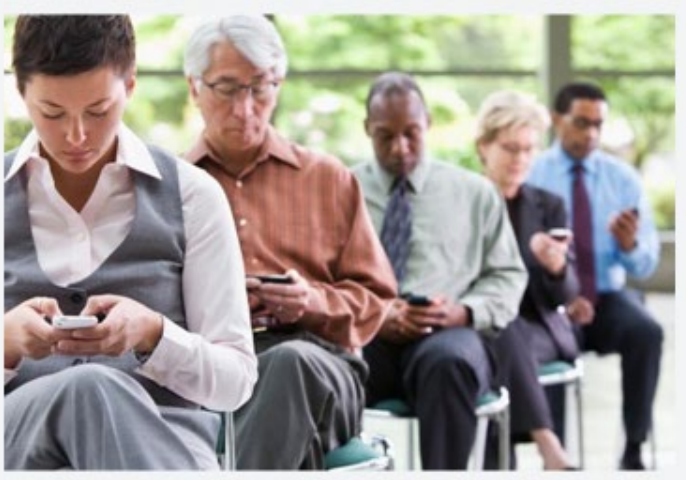


USING WHAT IS ALREADY THERE: EHR SMS

The EPIC charting system has SMS services built in.

Patients need to give permission to receive text appointment reminders

Patients can cancel or confirm via text as well.

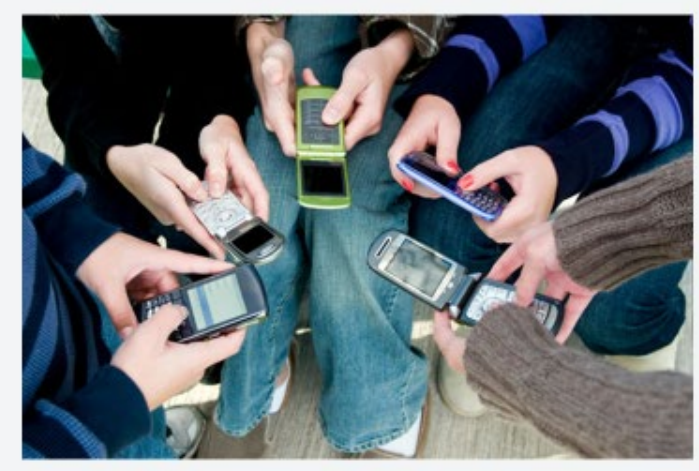

HOW TO SETUP SMS REMINDERS IN EPIC

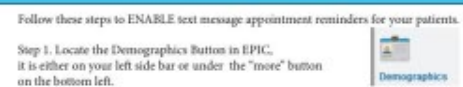

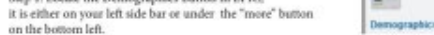

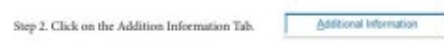

INSTRUCTIONS FOR STAFF

Updated visual instruction guide for version 2 roll out

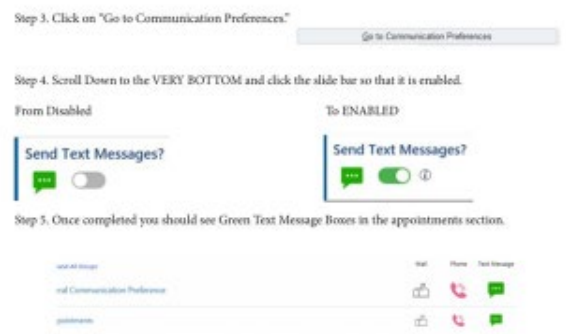

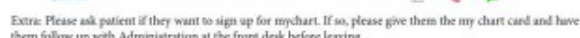
musk youm 

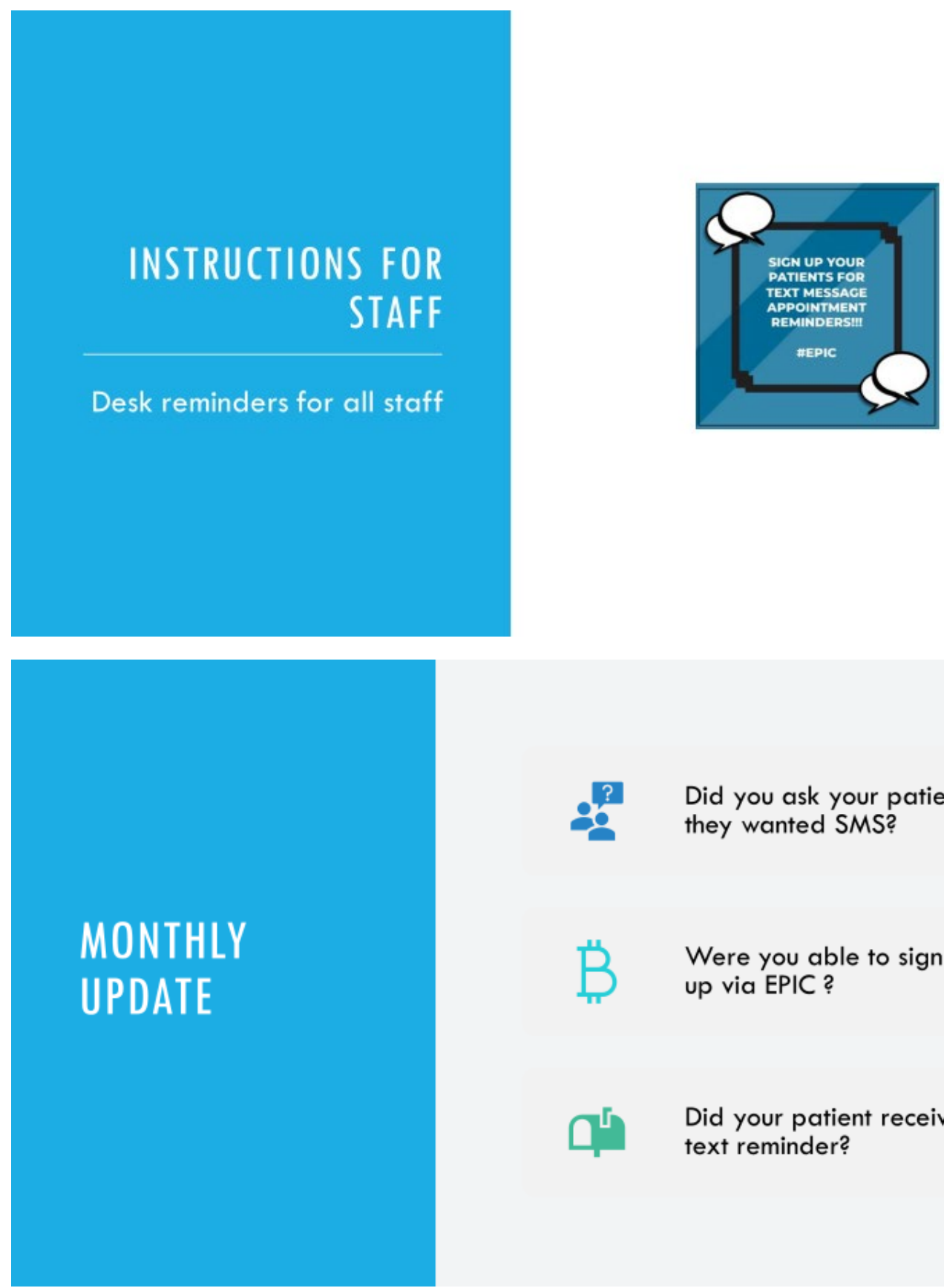

Did you ask your patients if they wanted SMS?

13ere you able to sign them up via EPIC?

Did your patient receive the text reminder? 


\section{NP rates $7.1 \%$ (down from $13.67 \%$ )}

Therapist $14.44 \%$ (up from $12.59 \%$ )

Residents $11.3 \%$

(down from 13.98\%)
ROUND 2 OF PROJECT

IMPLEMENTATION RESULTS (1 MO)

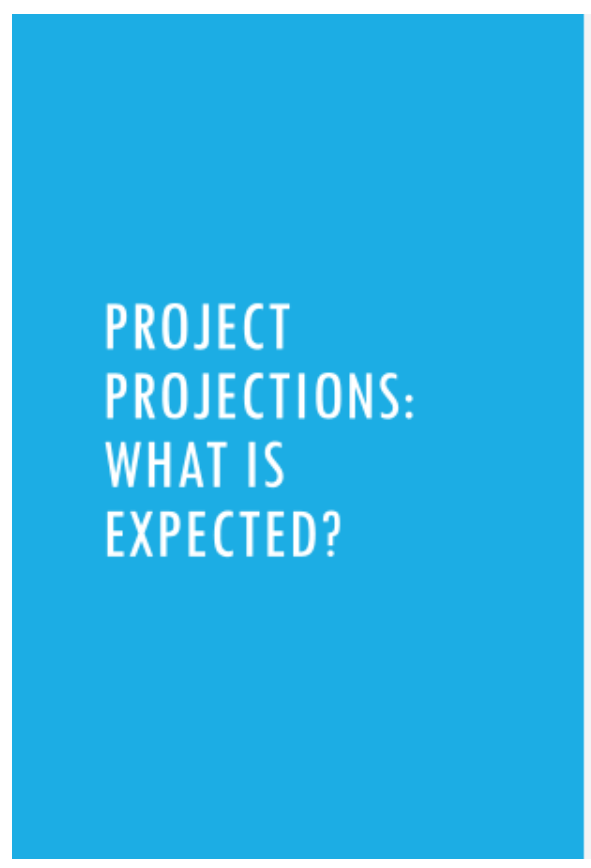

Considerations:

As the additional included staff (admin, therapist and residents) continue to participate in the project, there will be a continued reduction in no show rates for the clinic.

With the stay at home orders in place, and follow ups necessary for the prescription of refills, reminding patients to attend their video visits has become more important than ever.

The COVID19 Pandemic might act as an outlier, increasing virtual attendance and reducing no show rates out of necessity for all outpatient psychiatry patients. 
Continue Project Implementation

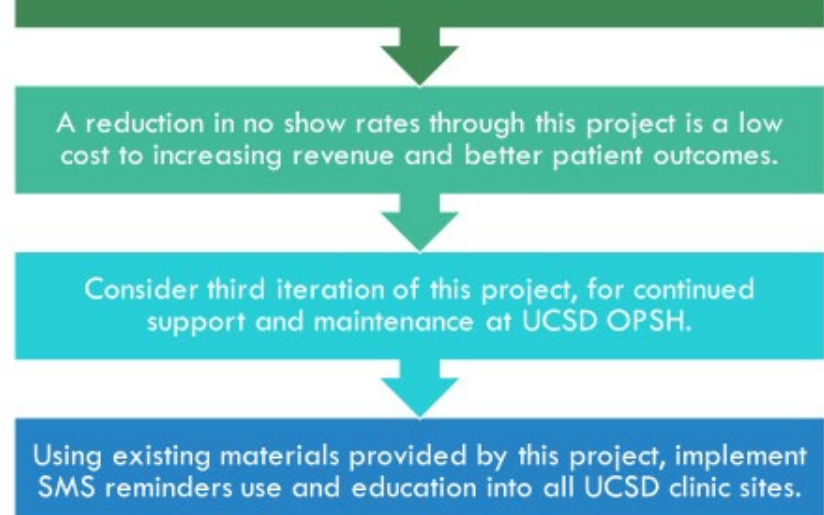

MOVING

FORWARD: WHAT

IS NEXT?
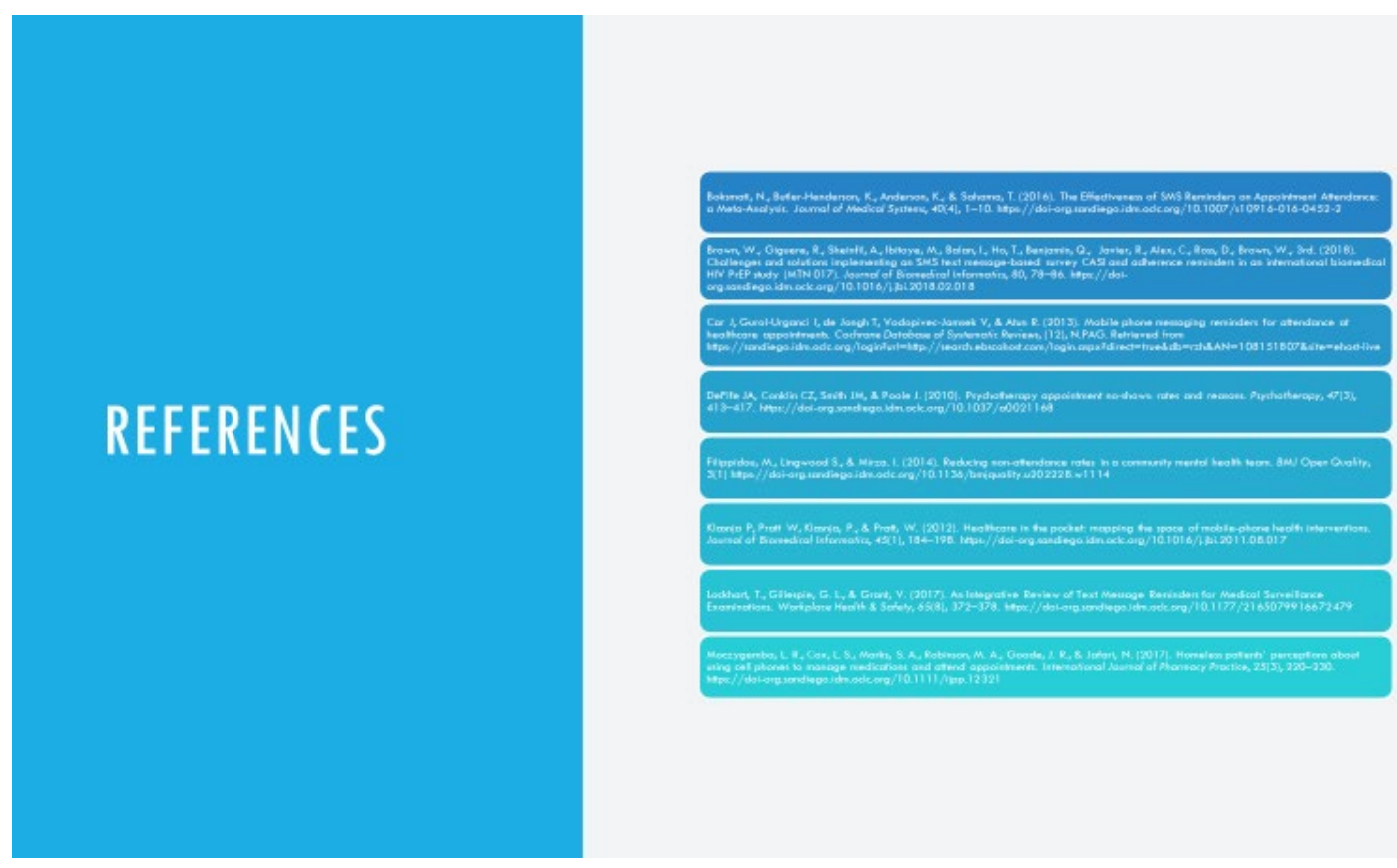
Appendix F

\section{AACN DNP Essentials/NONPF Competencies/ USD DNP Program Outcomes Exemplars}

\begin{tabular}{|c|c|c|}
\hline $\begin{array}{c}\text { AACN DNP Essentials \& NONPF } \\
\text { Competencies }\end{array}$ & $\begin{array}{c}\text { USD DNP Program } \\
\text { Objectives }\end{array}$ & $\begin{array}{l}\text { Exemplars } \\
\text { Provide bulleted exemplars that demonstrates } \\
\text { achievement of each objective }\end{array}$ \\
\hline $\begin{array}{l}\text { DNP Essential I: Scientific } \\
\text { Underpinnings for Practice } \\
\text { NONPF: Scientific Foundation } \\
\text { Competencies } \\
\text { The scientific foundation of nursing } \\
\text { practice has expanded and includes } \\
\text { a focus on both the natural and } \\
\text { social sciences including human } \\
\text { biology, genomics, science of } \\
\text { therapeutics, psychosocial sciences, } \\
\text { as well as the science of complex } \\
\text { organizational structures. In } \\
\text { addition, philosophical, ethical, } \\
\text { and historical issues inherent in the } \\
\text { development of science create a } \\
\text { context for the application of the } \\
\text { natural and social sciences. }\end{array}$ & $\begin{array}{l}\text { 2. Synthesize nursing and } \\
\text { other scientific and } \\
\text { ethical theories and } \\
\text { concepts to create a } \\
\text { foundation for advanced } \\
\text { nursing practice. }\end{array}$ & \begin{tabular}{|l} 
Fall 2017 \\
- \\
Pathophysiology peer review \\
article on disease process and \\
present evidence found on ground \\
rounds (APNC 520, Dr. \\
Maxwell) \\
- \\
Analyzed the application of \\
various translational science \\
methodological approaches in \\
advancing evidence based \\
practice. (DNPC 611, Dr. \\
Burkard) \\
Spring 2018 \\
Reviewed pharmacologic \\
treatments of diseases with \\
considerations to special \\
populations (APNC 523, Dr. \\
Hoyt) \\
Analyzed approaches to the \\
development, monitoring, and \\
modification of the therapeutic
\end{tabular} \\
\hline
\end{tabular}




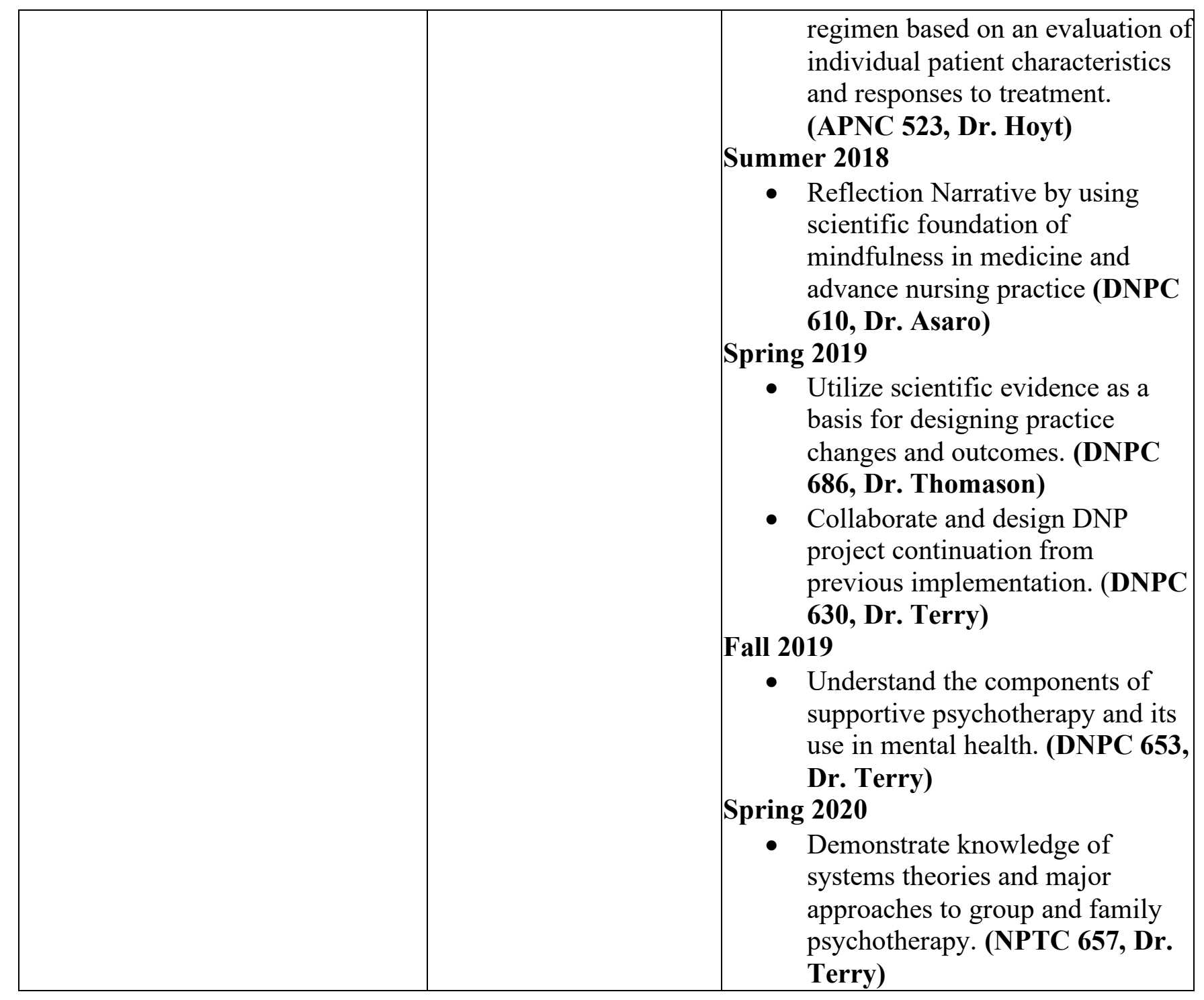




\begin{tabular}{|c|c|c|}
\hline $\begin{array}{l}\text { DNP Essential II: Organizational } \\
\text { \& System Leadership for Quality } \\
\text { Improvement \& Systems } \\
\text { Thinking } \\
\text { NONPF: Leadership } \\
\text { Competencies/Health Delivery } \\
\text { System Competencies } \\
\text { Advanced nursing practice includes } \\
\text { an organizational and systems } \\
\text { leadership component that } \\
\text { emphasizes practice, ongoing } \\
\text { improvement of health outcomes, } \\
\text { and ensuring patient safety. Nurses } \\
\text { should be prepared with } \\
\text { sophisticated expertise in assessing } \\
\text { organizations, identifying system's } \\
\text { issues, and facilitating } \\
\text { organization- wide changes in } \\
\text { practice delivery. This also requires } \\
\text { political skills, systems thinking, } \\
\text { and the business and financial } \\
\text { acumen needed for the analysis of } \\
\text { practice quality and costs. }\end{array}$ & $\begin{array}{l}\text { 5. Design, implement, } \\
\text { and evaluate ethical } \\
\text { health care delivery } \\
\text { systems and information } \\
\text { systems that meet } \\
\text { societal needs and ensure } \\
\text { accountability for quality } \\
\text { outcomes. }\end{array}$ & \begin{tabular}{|l} 
Fall 2017 \\
Critically analyzed and applied \\
appropriate statistical procedures \\
for various translational / \\
evidence based science designs \\
(DNPC 611, Dr. Burkard) \\
- \\
Used epidemiologic models to \\
explore factors contributing to a \\
selected health problems \\
encountered in advanced nursing \\
practice within population groups. \\
(DNPC 625, Dr. Barger). \\
Spring 2018 \\
Examined the furnishing of drugs \\
and/or devices pursuant to the \\
California BRN practice \\
requirements, standardized \\
procedures, and in conformance \\
with applicable laws, codes, \\
and/or regulations. (APNC 523, \\
Dr. Hoyt) \\
Demonstrated knowledge of \\
California Pharmacy Board rules \\
and regulations, California Health \\
\&amp; Safety Codes, and the \\
Federal Register. (APNC 523, \\
Dr. Hoyt) \\
Analyzed and applied strategic \\
management principles in a case
\end{tabular} \\
\hline
\end{tabular}




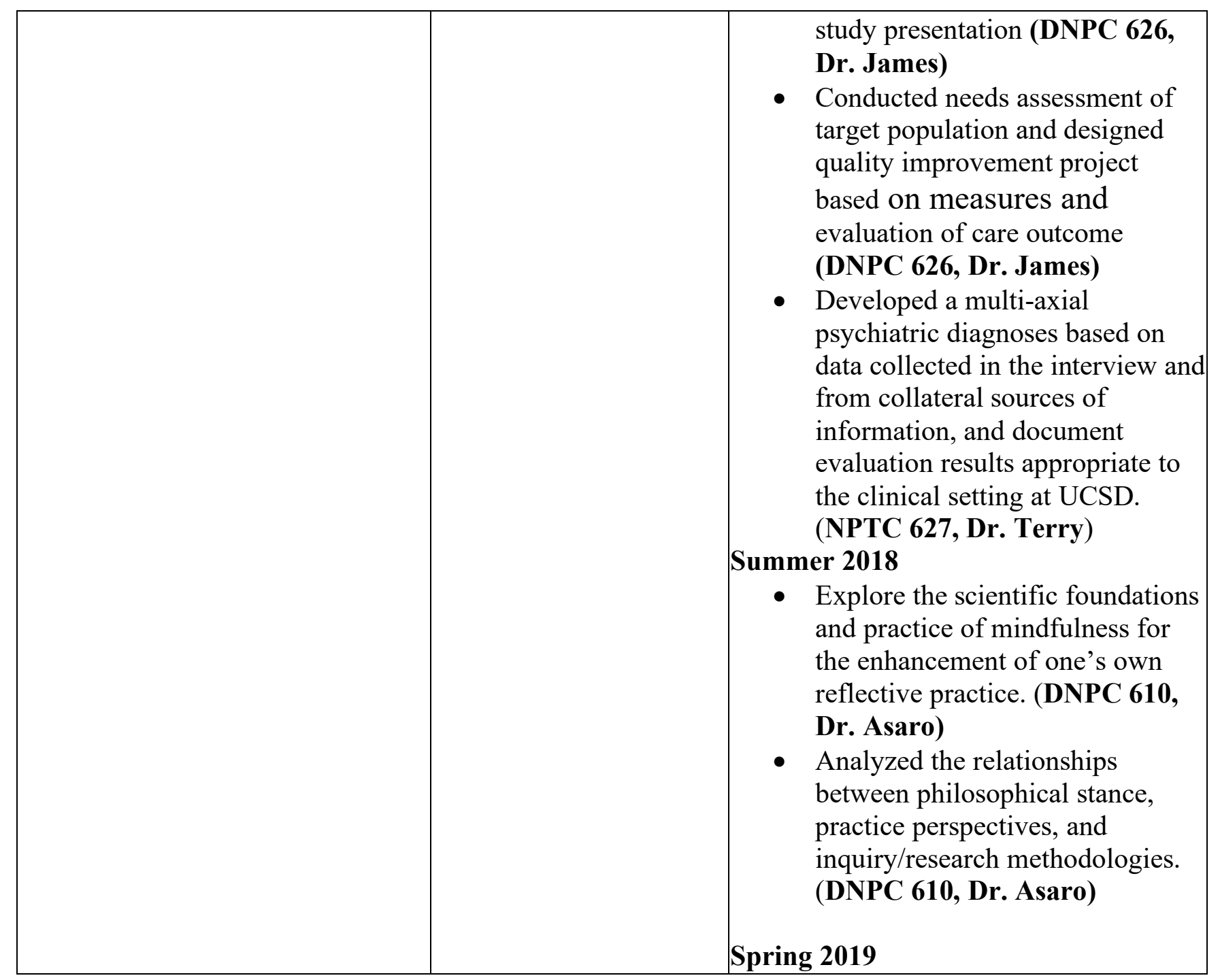




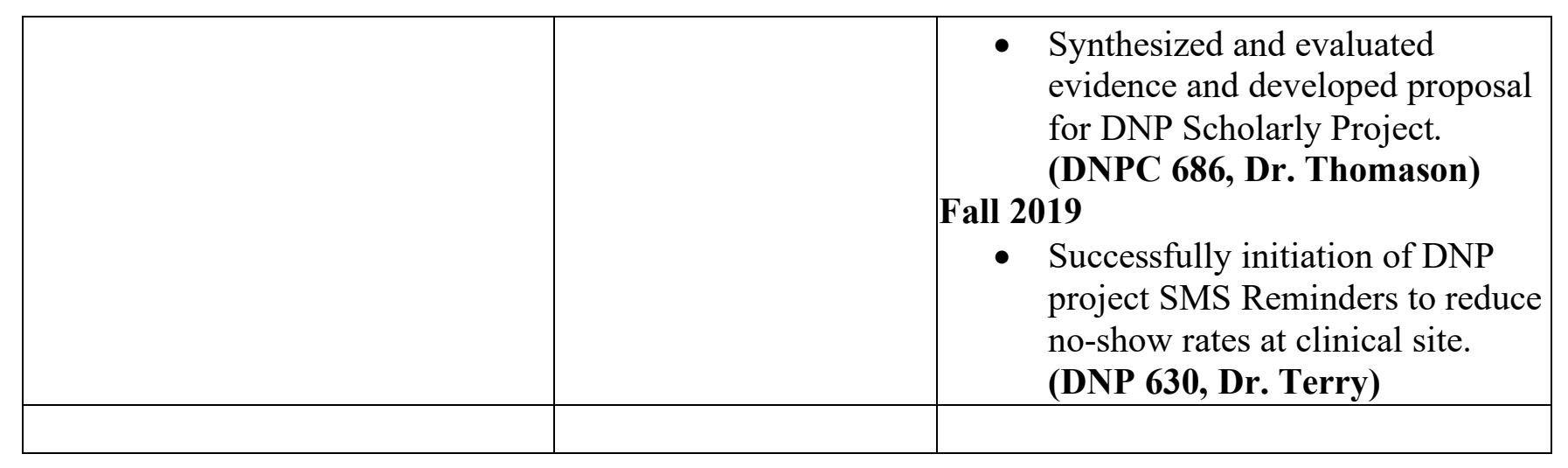

\begin{tabular}{|c|c|c|}
\hline $\begin{array}{l}\text { Scholarship \& Analytical } \\
\text { Methods for Evidence-Based } \\
\text { Practice } \\
\text { NONPF: Quality } \\
\text { Competencies/Practice Inquiry } \\
\text { Competencies } \\
\text { Scholarship and research are the } \\
\text { hallmarks of doctoral education. } \\
\text { Although basic research is viewed } \\
\text { as the first and most essential } \\
\text { form of scholarly activity, an } \\
\text { enlarged perspective of } \\
\text { scholarship has emerged through } \\
\text { alternative paradigms that involve }\end{array}$ & $\begin{array}{l}\text { 4. Incorporate research } \\
\text { into practice through } \\
\text { critical appraisal of } \\
\text { existing evidence, } \\
\text { evaluating practice } \\
\text { outcomes, and developing } \\
\text { evidence-based practice } \\
\text { guidelines. }\end{array}$ & \begin{tabular}{|l} 
Fall 2017 \\
- \\
Evaluated data management \\
techniques to monitor and \\
evaluate evidence-based \\
interventions, at clinical setting. \\
(DNPC 625, Dr. Barger) \\
- CITI program training completion \\
on biomedical research, conflict \\
of interest, and social behavioral \\
conduct in research (DNPC 625, \\
Dr. Barger) \\
Spring 2018 \\
- Synthesized and disseminated \\
evidence-based research in \\
Complementary and Alternative \\
Medicine Modalities
\end{tabular} \\
\hline
\end{tabular}




\begin{tabular}{|c|c|}
\hline $\begin{array}{l}\text { more than discovery of new } \\
\text { knowledge. These paradigms } \\
\text { recognize: (1) the scholarship of } \\
\text { discovery and integration } \\
\text { "reflects the investigative and } \\
\text { synthesizing traditions of } \\
\text { academic life"; (2) scholars give } \\
\text { meaning to isolated facts and } \\
\text { make connections across } \\
\text { disciplines through the } \\
\text { scholarship of integration; and (3) } \\
\text { the scholar applies knowledge to } \\
\text { solve a problem via the } \\
\text { scholarship of application that } \\
\text { involves the translation of } \\
\text { research into practice and } \\
\text { dissemination and integration of } \\
\text { new knowledge. }\end{array}$ & \begin{tabular}{|l} 
Presentation: Cranberry (APNC \\
523, Dr. Hoyt) \\
Fall 2018 \\
- \\
Developed evidence-based \\
manuscript to prepare for \\
submission "G6PD" (DNPC 622, \\
Dr. Nolen) \\
- Identified key contributions to the \\
comprehensive biopsychosocial \\
understanding of normal and \\
abnormal human behaviors. \\
(NPTC 627, Dr. Terry) \\
Demonstrate knowledge of basic \\
neuroscience, including brain \\
structure and function, damage \\
effects, and the related \\
psychopathologies. (NPTC 627, \\
Dr. Terry) \\
Spring 2019 \\
Maintained clinical standards by \\
attending the San Diego critical \\
care conference for psychiatry \\
UCSD. (NPTC 651, Dr. Terry) \\
Fall 2019 \\
Conduct psychotherapy sessions \\
in selected clinical settings, \\
incorporating appropriate verbal \\
and non-verbal approaches. \\
(NPTC 653, Dr. Terry)
\end{tabular} \\
\hline
\end{tabular}




\begin{tabular}{|c|c|c|}
\hline & & 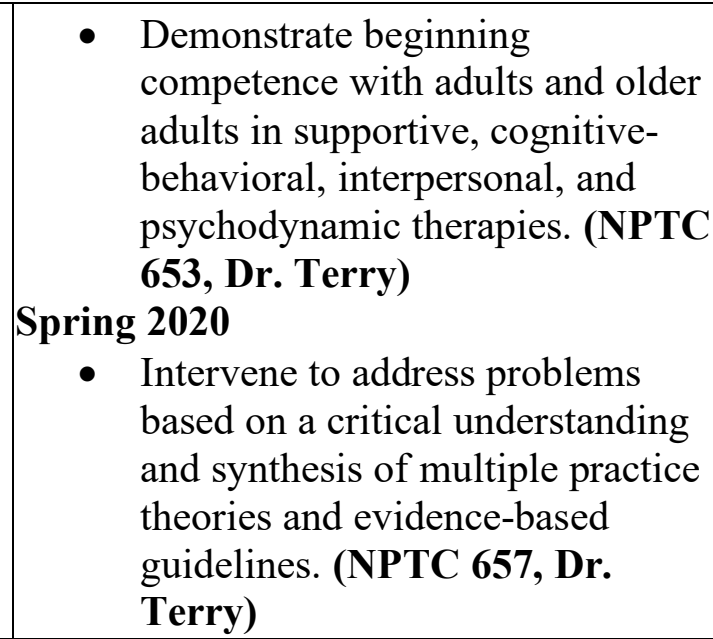 \\
\hline $\begin{array}{l}\text { DNP Essential IV: Information } \\
\text { Systems/Technology \& Patient } \\
\text { Care Technology for } \\
\text { Improvement \& } \\
\text { Transformation of Health Care } \\
\text { NONPF: Technology \& } \\
\text { Information Literacy } \\
\text { Competencies } \\
\text { DNP graduates are distinguished } \\
\text { by their abilities to use } \\
\text { information systems/technology to } \\
\text { support and improve patient care } \\
\text { and health care systems, and } \\
\text { provide leadership within health } \\
\text { care systems and/or academic }\end{array}$ & $\begin{array}{l}\text { 7. Incorporate ethical, } \\
\text { regulatory, and legal } \\
\text { guidelines in the delivery } \\
\text { of health care and the } \\
\text { selection, use, and } \\
\text { evaluation of information } \\
\text { systems and patient care } \\
\text { technology. }\end{array}$ & \begin{tabular}{|c} 
Fall 2017 \\
- Obtained Biomedical Research \\
Human Certification- \\
Basic/Refresher Course through \\
CITI (DNPC 625, Dr. Barger) \\
Spring 2018 \\
- Examined and explored \\
improvements toward \\
incorporating HIPPA guidelines \\
into electronic healthcare record \\
interfaces (APNC 521, Dr Hoyt.) \\
Analyzed the health care \\
environment of UCSD OPSH \\
clinic, prepared a strategic \\
plan appropriate for the \\
environment, and developed \\
implementation steps for the
\end{tabular} \\
\hline
\end{tabular}




\begin{tabular}{|c|c|}
\hline $\begin{array}{l}\text { Settings. Knowledge and skills } \\
\text { related to information } \\
\text { systems/technology and patient } \\
\text { care technology prepare the DNP } \\
\text { graduates apply new knowledge, } \\
\text { manage individual and aggregate } \\
\text { level }\end{array}$ & $\begin{array}{l}\text { accomplishment of the strategic } \\
\text { plan. (DNPC 625, Dr. James) } \\
\text { Used advanced communication } \\
\text { skills and processes to lead } \\
\text { quality improvement and patient } \\
\text { safety initiatives at UCSD clinical } \\
\text { site. (DNPC 625, Dr. James) } \\
\text { Summer } 2018 \\
\text { - Apply principle of health care } \\
\text { finance, needs assessment, } \\
\text { strategic planning models, and } \\
\text { SWOT analysis in order to } \\
\text { develop a health care product } \\
\text { proposal regarding EHR on a } \\
\text { video platform (DNPC 653, Dr. } \\
\text { Gonzales) } \\
\text { Fall 2018 } \\
\text { Gained exposure to multiple } \\
\text { EMRs in clinical site EPIC and } \\
\text { Cerner, with a focus on patient } \\
\text { center technology (NPTC 627, } \\
\text { Dr. Terry) } \\
\text { Explore current therapies and } \\
\text { investigational interventions } \\
\text { including pharmacogenetics for } \\
\text { complex disease states in the } \\
\text { acutely or chronically ill } \\
\text { individual utilizing evidence- }\end{array}$ \\
\hline
\end{tabular}




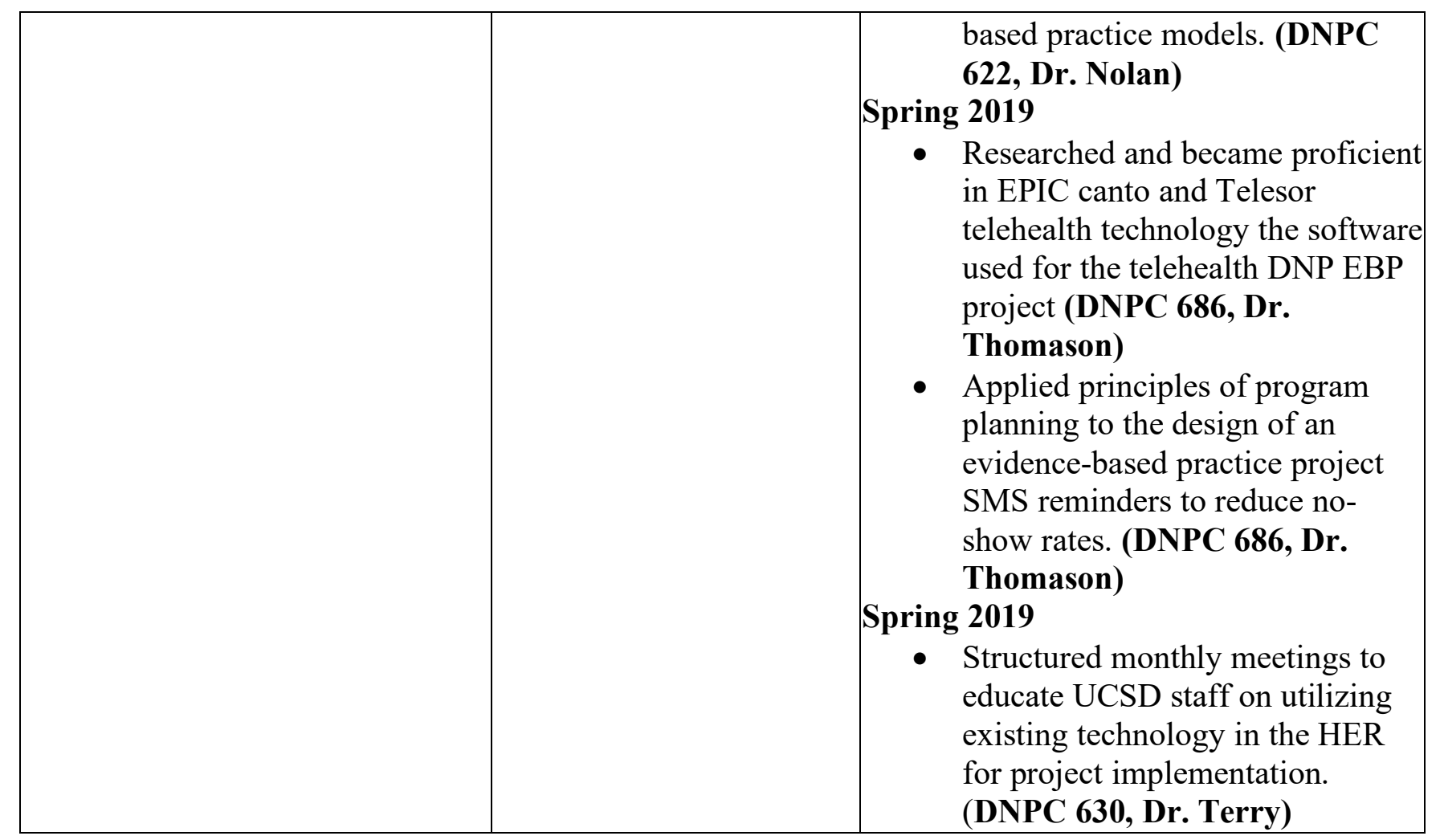

information, and assess the

efficacy of patient care technology appropriate to a specialized area of practice along with the design, selection, and use of information systems/technology to evaluate 


\begin{tabular}{|c|c|c|}
\hline \begin{tabular}{|l|} 
programs of care, outcomes of \\
care, and care systems. \\
Information systems/technology \\
provide a mechanism to apply \\
budget and productivity tools, \\
practice information systems and \\
decision supports, and web- based \\
learning or intervention tools to \\
support and improve patient care.
\end{tabular} & & \\
\hline $\begin{array}{l}\text { DNP Essential V: Health Care } \\
\text { Policy for Advocacy in Health } \\
\text { Care } \\
\text { NONPF: Policy Competencies } \\
\text { Health care policy, whether } \\
\text { created though governmental } \\
\text { actions, institutional decision- } \\
\text { making, or organizational } \\
\text { standards, creates a framework } \\
\text { that can facilitate or impede the } \\
\text { delivery of health care services or } \\
\text { the ability of the provider to } \\
\text { engage in practice to address } \\
\text { health care needs. Engagement in } \\
\text { the process of policy development } \\
\text { is central to creating a health care } \\
\text { system that meets the needs of its } \\
\text { constituents. Political activism and } \\
\text { a commitment to policy }\end{array}$ & $\begin{array}{l}\text { 3. Demonstrate leadership in } \\
\text { collaborative efforts to } \\
\text { develop and implement } \\
\text { policies to improve health } \\
\text { care delivery and outcomes } \\
\text { at all levels of professional } \\
\text { practice (institutional, local, } \\
\text { state, regional, national, } \\
\text { and/or international). }\end{array}$ & \begin{tabular}{|l} 
Spring 2018 \\
- \\
Proposed licensing restrictions \\
removal for nurse practitioners \\
to local congress representative \\
(DNPC 648, Dr. Burkard) \\
- Examined the impact of legal \\
and regulatory issues on health \\
care delivery and advanced \\
nursing practice roles. (DNPC \\
648, Dr. Burkard) \\
- Conducted a policy analysis of \\
HR4778 using a theoretical \\
framework. (DNPC 648, Dr. \\
Burkard) \\
Fall 2019 \\
Patient presented meeting \\
criteria for active suicidal \\
ideation with previous SA, \\
initiated protocol for active SI, \\
and escorted the patient to
\end{tabular} \\
\hline
\end{tabular}




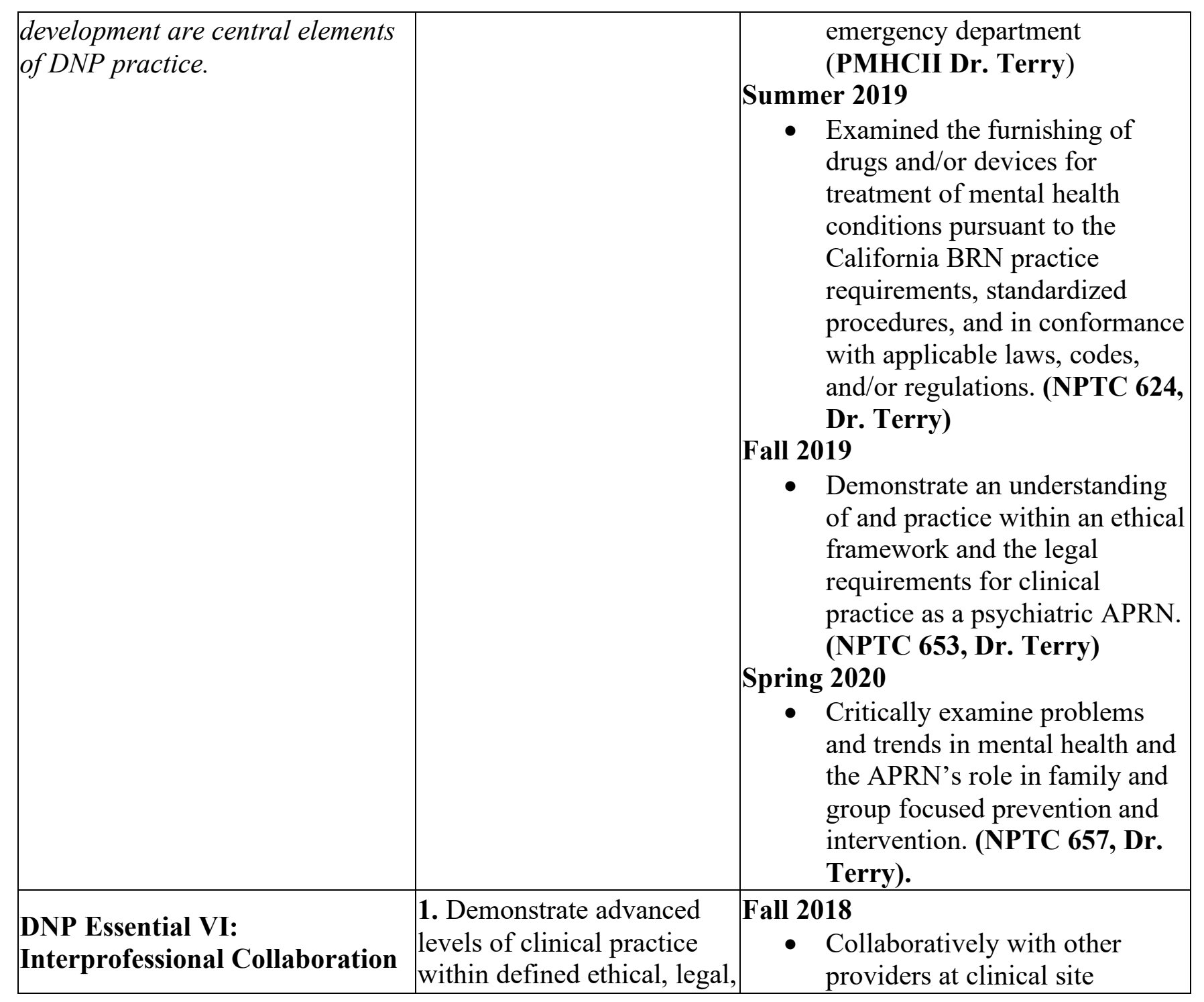




\begin{tabular}{|c|c|c|}
\hline $\begin{array}{l}\text { for Improving Patient \& } \\
\text { Population Health Outcomes } \\
\text { NONPF: Leadership } \\
\text { Competencies } \\
\text { Today's complex, multi-tiered } \\
\text { health care environment depends } \\
\text { on the contributions of highly } \\
\text { skilled and knowledgeable } \\
\text { individuals from multiple } \\
\text { professions. In order to } \\
\text { accomplish the IOM mandate for } \\
\text { safe, timely, effective, efficient, } \\
\text { equitable, and patient-centered }\end{array}$ & $\begin{array}{l}\text { and regulatory parameters in } \\
\text { designing, implementing, } \\
\text { and evaluating evidenced- } \\
\text { based, culturally competent } \\
\text { therapeutic interventions for } \\
\text { individuals or aggregates. } \\
\text { 3. Demonstrate leadership }\end{array}$ & $\begin{array}{l}\text { synthesized multidisciplinary } \\
\text { methods of behavioral change, } \\
\text { including contributions from } \\
\text { health psychology, behavioral } \\
\text { medicine. (NPTC 627, Dr. } \\
\text { Terry) } \\
\text { Spring } 2019 \\
\text { Formulated a plan for effective } \\
\text { dissemination of evaluation } \\
\text { results to appropriate } \\
\text { stakeholders at UCSD OPSH. } \\
\text { (DPNC 686, Dr. Thomason). } \\
\text { Presented patient cases orally in } \\
\text { an organized, succinct, and } \\
\text { accurate manner in morning } \\
\text { briefings. (NPTC 651, Dr. } \\
\text { Terry) } \\
\text { Articulate and demonstrate the } \\
\text { collaborative role of a } \\
\text { psychiatric APRN provider of } \\
\text { psychotherapy with other } \\
\text { disciplines. (NPTC 651, Dr. } \\
\text { Terry) } \\
\text { Spring } 2020 \\
\text { DNP project rollout, reduction } \\
\text { in no-show rates produced, } \\
\text { continued expansion of the } \\
\text { project proposed. (DNP 630, } \\
\text { Dr. Terry). }\end{array}$ \\
\hline
\end{tabular}




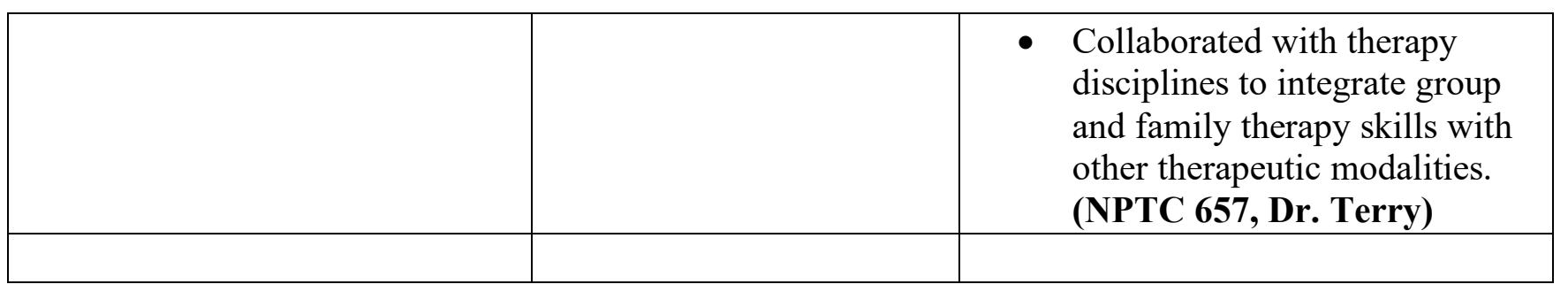

\begin{tabular}{|c|c|c|}
\hline $\begin{array}{l}\text { care in this environment, health } \\
\text { care professionals must function } \\
\text { as highly collaborative teams. } \\
\text { DNPs have advanced preparation } \\
\text { in the interprofessional dimension } \\
\text { of health care that enable them to } \\
\text { facilitate collaborative team } \\
\text { functioning and overcome } \\
\text { impediments to interprofessional } \\
\text { practice. DNP graduates have } \\
\text { preparation in methods of effective } \\
\text { team leadership and are prepared } \\
\text { to play a central role in } \\
\text { establishing interprofessional } \\
\text { teams, participating in the work of } \\
\text { the team, and assuming leadership } \\
\text { of the team when appropriate. }\end{array}$ & $\begin{array}{l}\text { in collaborative efforts to } \\
\text { develop and implement } \\
\text { policies to improve health } \\
\text { care delivery and outcomes } \\
\text { at all levels of professional } \\
\text { practice (institutional, local, } \\
\text { state, regional, national, } \\
\text { and/or international). }\end{array}$ & \\
\hline $\begin{array}{l}\text { DNP Essential VII: Clinical } \\
\text { Prevention \& Population Health } \\
\text { for Improving Nation's Health }\end{array}$ & $\begin{array}{l}\text { 6. Employ a population } \\
\text { health focus in the design, } \\
\text { implementation, and } \\
\text { evaluation of health care }\end{array}$ & $\begin{array}{l}\text { Fall } 2017 \\
\text { - Analyses data and measures of } \\
\text { disease in population (DNPC } \\
\text { 625, Dr. Barger) }\end{array}$ \\
\hline
\end{tabular}




\begin{tabular}{|c|c|c|}
\hline $\begin{array}{l}\text { NONPF: Leadership } \\
\text { Competencies } \\
\text { Consistent with national calls for } \\
\text { action and with the longstanding } \\
\text { focus on health promotion and } \\
\text { disease prevention in nursing, the } \\
\text { DNP graduate has a foundation in } \\
\text { clinical prevention and population } \\
\text { health. This foundation enables } \\
\text { DNP graduates to analyze } \\
\text { epidemiological, biostatistical, } \\
\text { occupational, and environmental } \\
\text { data in the development, } \\
\text { implementation, and evaluation of } \\
\text { clinical prevention and } \\
\text { population. }\end{array}$ & $\begin{array}{l}\text { delivery systems that } \\
\text { address primary, secondary, } \\
\text { and tertiary levels of } \\
\text { prevention. }\end{array}$ & 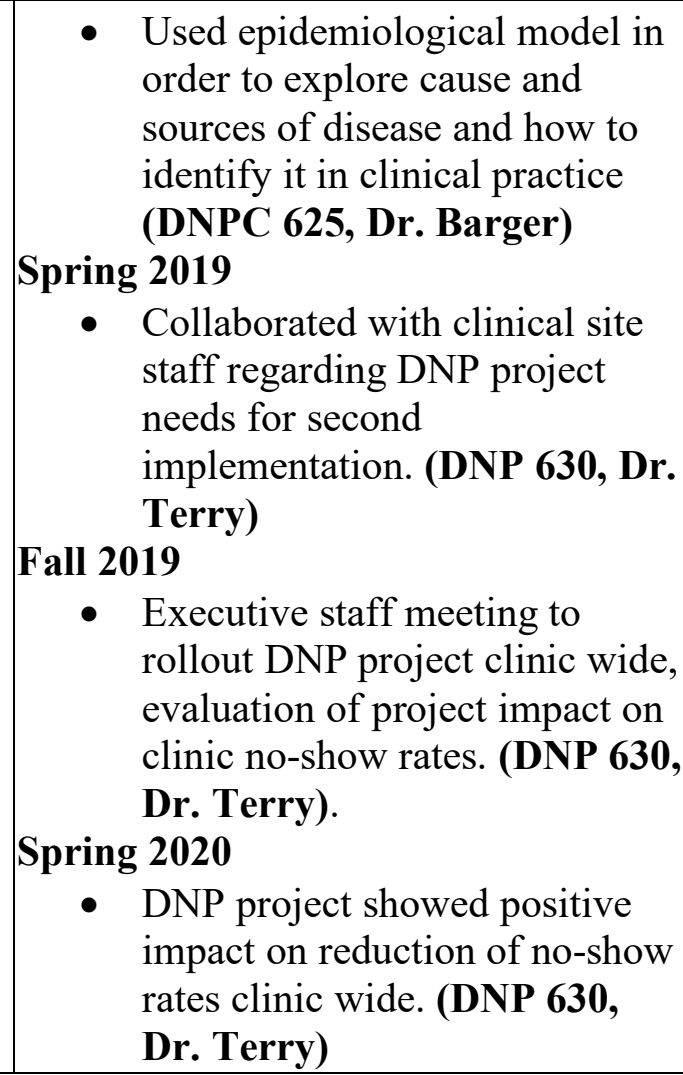 \\
\hline
\end{tabular}

\begin{tabular}{|c|c|c|}
\hline $\begin{array}{l}\text { DNP Essential VIII: Advanced } \\
\text { Nursing Practice }\end{array}$ & $\begin{array}{l}\text { 1. Demonstrate advanced } \\
\text { levels of clinical practice } \\
\text { within defined ethical, legal, } \\
\text { and regulatory parameters in } \\
\text { designing, implementing, }\end{array}$ & $\begin{array}{l}\text { Fall } 2018 \\
\text { - Applied a biopsychosocial } \\
\text { approach to disease prevention/ } \\
\text { health promotion practices with } \\
\text { psychiatric patients across the }\end{array}$ \\
\hline
\end{tabular}




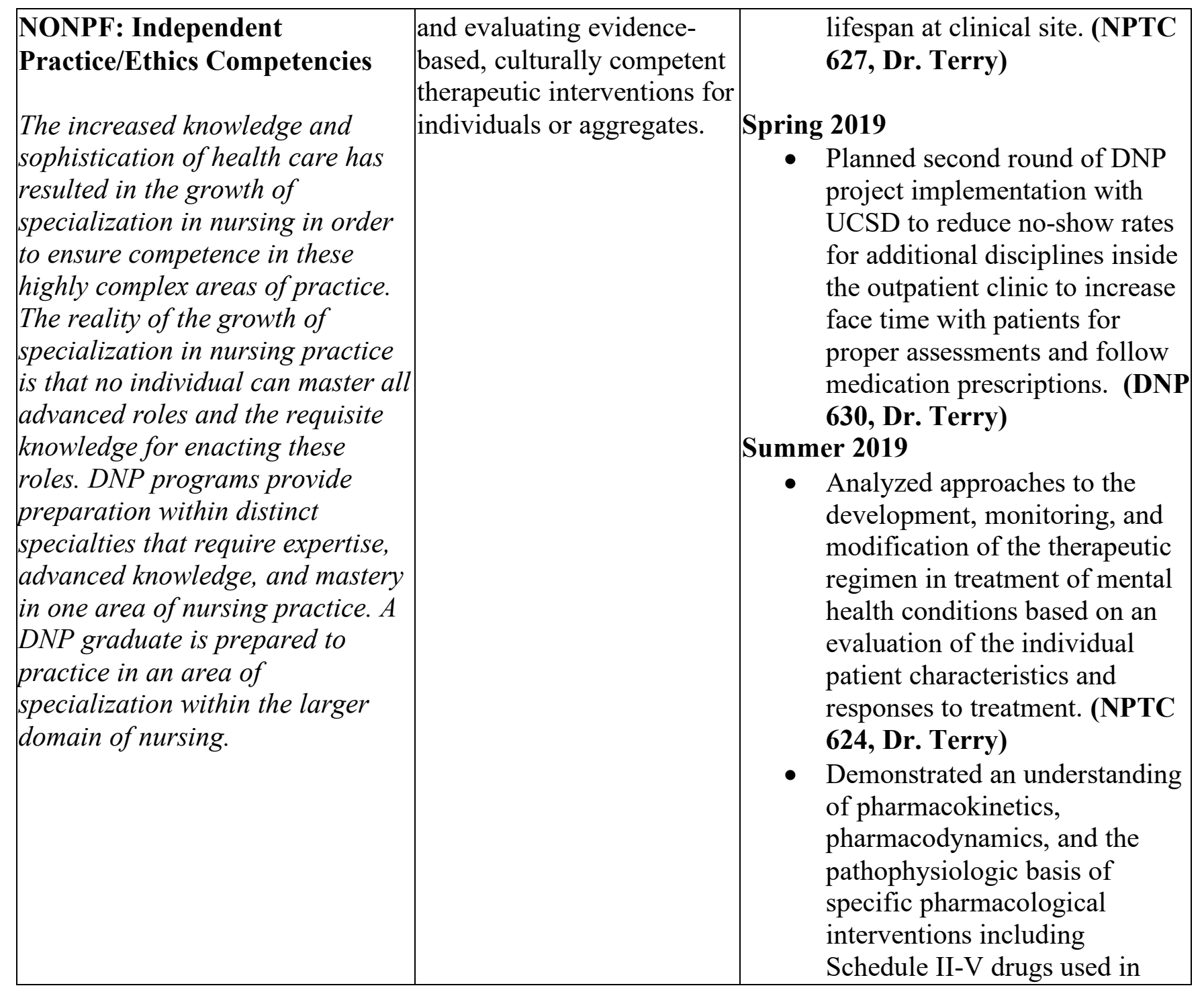




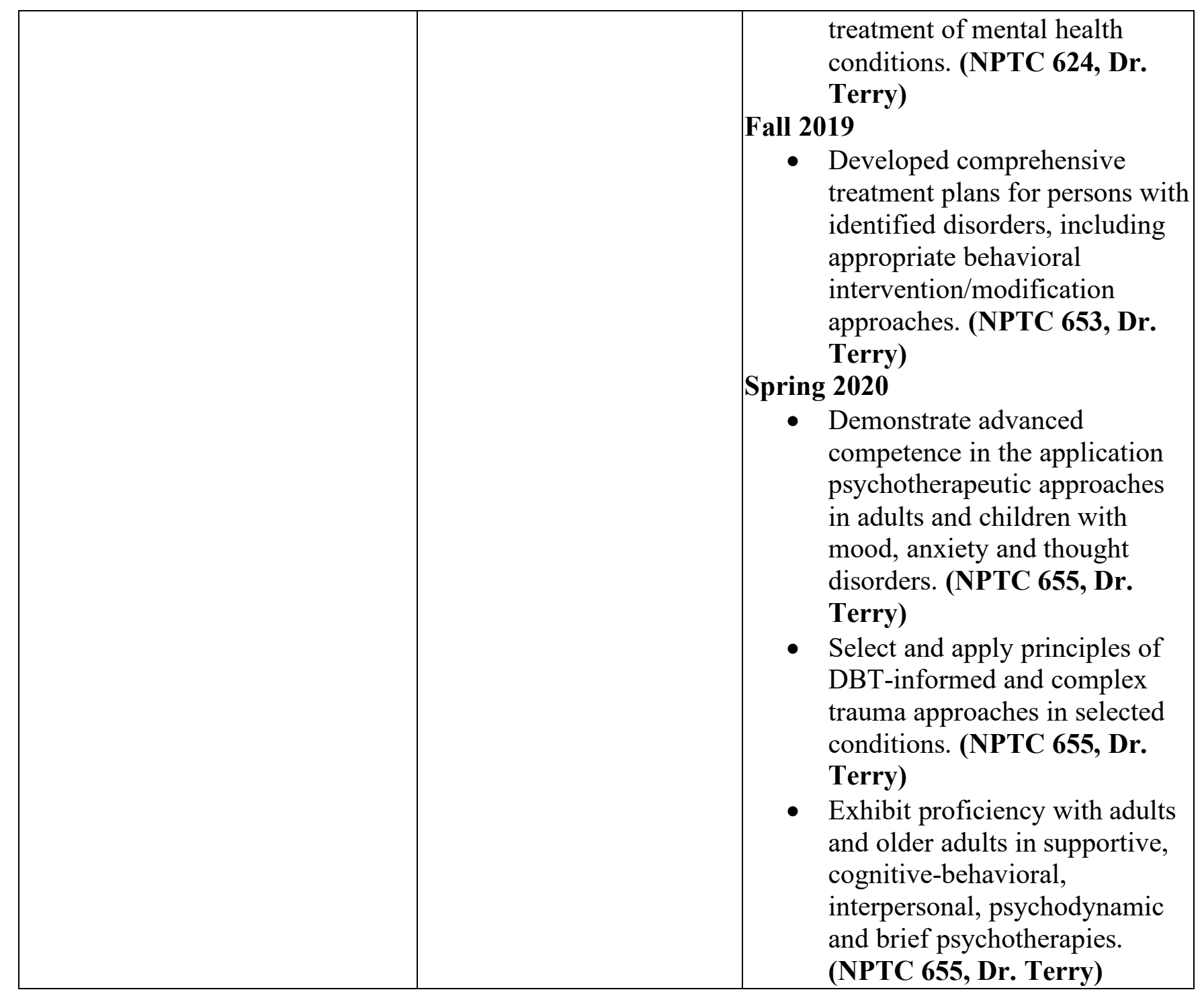




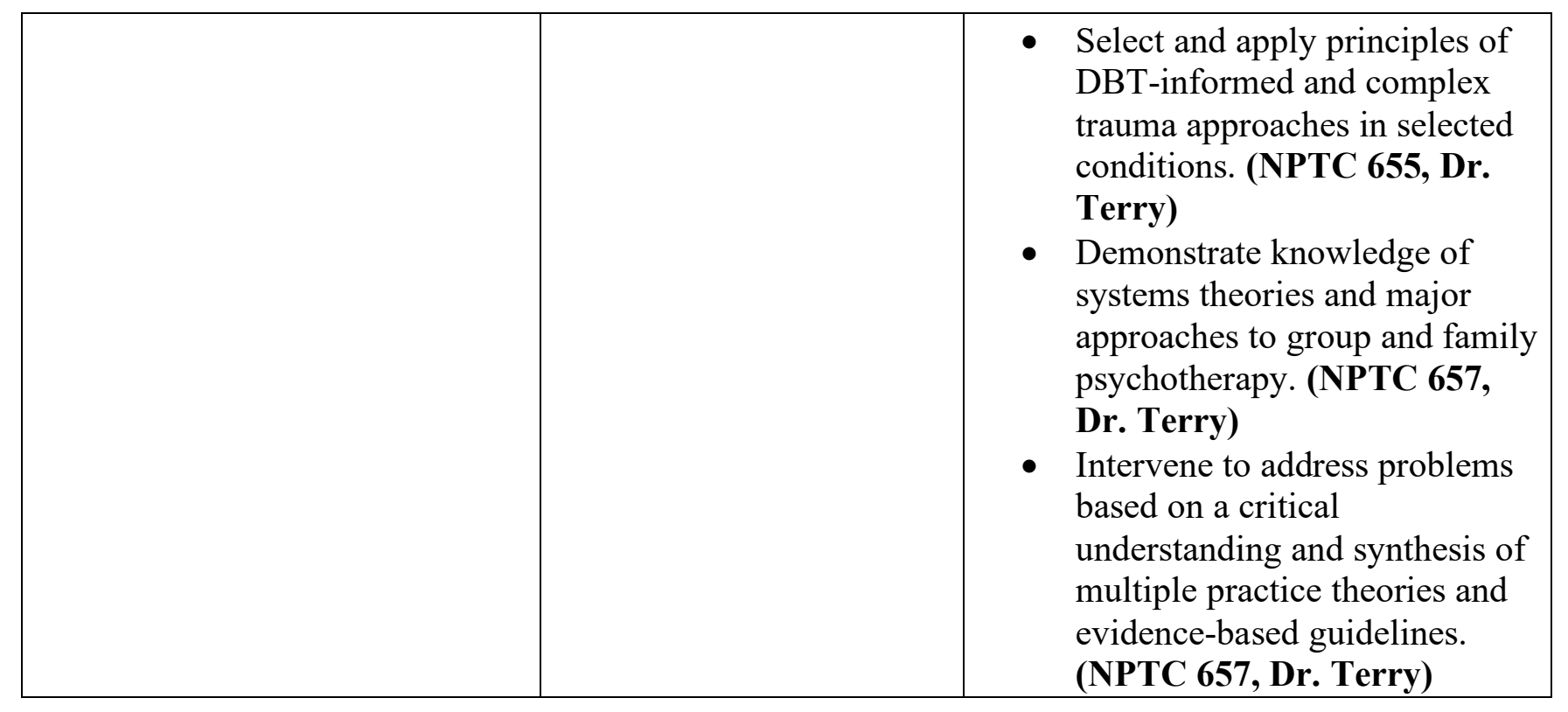


Appendix G

[Other Supporting Documents]

\section{HOW TO SETUP SMS REMINDERS IN EPIC}

Follow these steps to ENABLE text message appointment reminders for your patients.

Step 1. Locate the Demographics Button in EPIC,

it is either on your left side bar or under the "more" button on the bottom left.

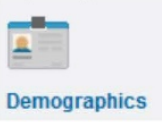

Step 2. Click on the Addition Information Tab.

Additional Information

Step 3. Click on "Go to Communication Preferences."

Go to Communication Preferences

Step 4. Scroll Down to the VERY BOTTOM and click the slide bar so that it is enabled.

From Disabled

Send Text Messages?

$\cdots$

Step 5. Once completed you should see Green Text Message Boxes in the appointments section.

$$
\text { To ENABLED }
$$

Send Text Messages?

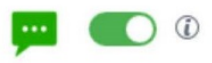

land All Groups

tral Communication Preference

pointments

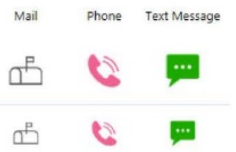

Mall Phone Text Message

무웅

Extra: Please ask patient if they want to sign up for mychart. If so, please give them the my chart card and have them follow up with Administration at the front desk before leaving. 


\section{Appendix H}

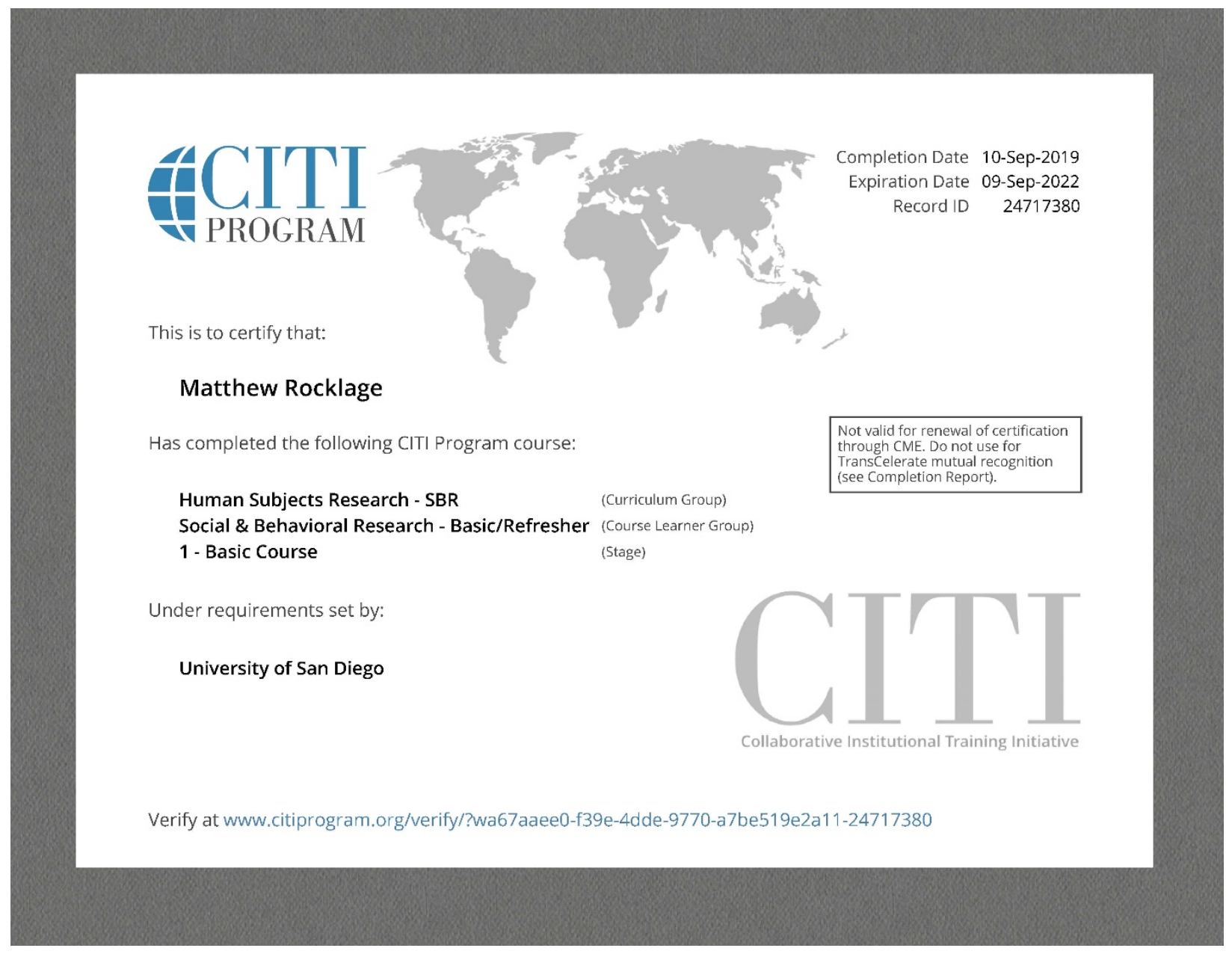




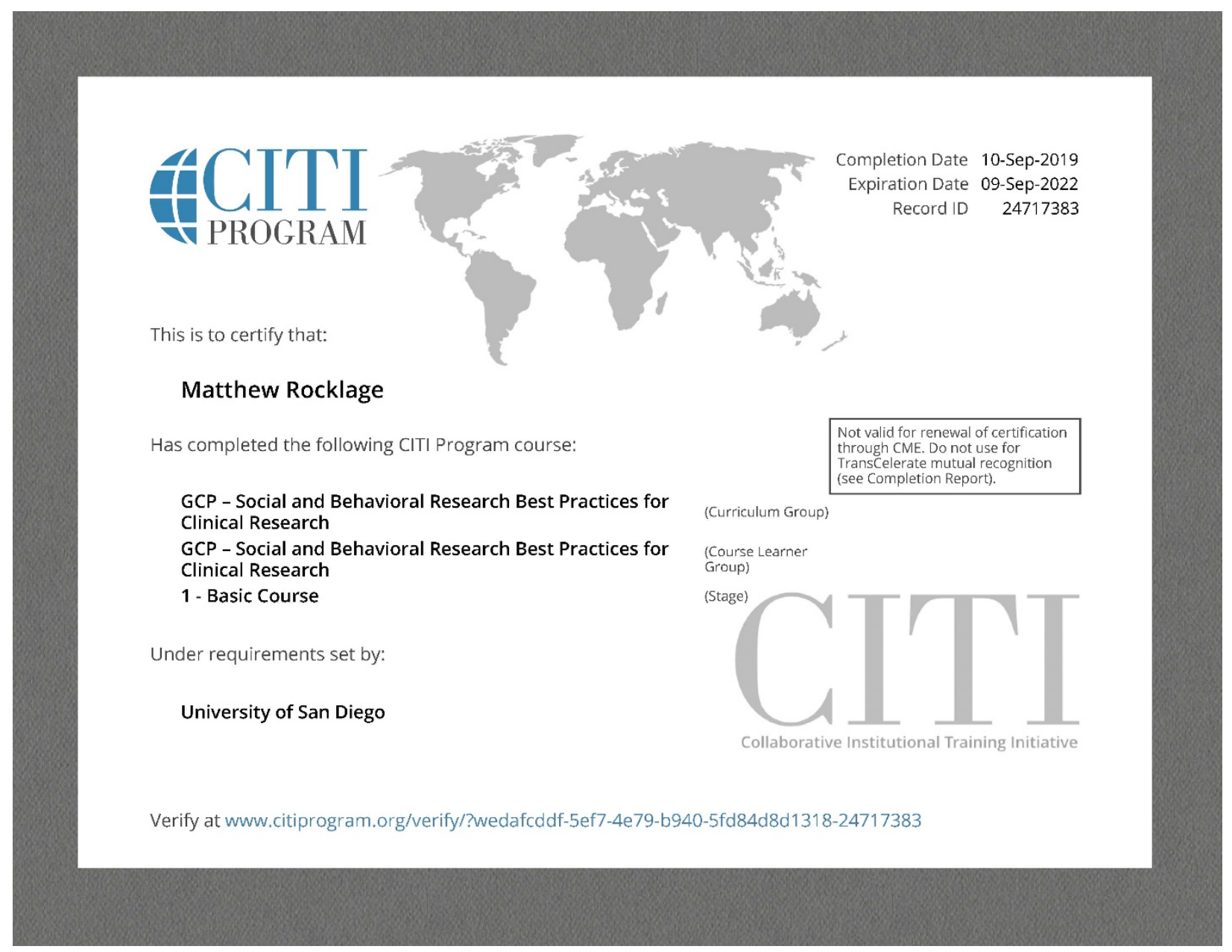

